\title{
An Assessment of Wheelchair Provision in the Majority World With a Focus on Uganda through Fieldwork
}

\author{
by \\ Neil Voorneveld
}

A thesis submitted to the Faculty of Graduate and Postdoctoral Affairs in partial fulfillment of the requirements for the degree of

Master of Design

in

Industrial Design

Carleton University

Ottawa, Ontario

(C) 2015, Neil Voorneveld 


\section{Abstract}

This research provides an assessment of wheelchair provision for people with disabilities in the majority world. The research was conducted through a series of questionnaires, interviews, and observations with multiple stakeholders to gain different perspectives on the same topic. It discusses the limitations of national small-scale wheelchair provision, the limitations of international large-scale wheelchair provision, and the state of wheelchair service-delivery in the majority world. The research with international large-scale wheelchair producers was conducted in Canada, while the research with the remaining stakeholders was done during fieldwork over a ten day period in Uganda. The results of the research provide several insights into wheelchair provision, including limitations to standardization, resources, business training, micro-logistics and reverse-logistics. While wheelchair service-delivery is present in Uganda, it is not regulated or consistent among national small-scale wheelchair producers and international large-scale wheelchair producers.

Keywords: universal design, assistive devices, wheelchair provision, majority world. 


\section{Acknowledgements}

Family: Thank you to the best parents ever, Glenna and Robert Voorneveld—and a great sister, Holly Voorneveld. The opportunities that you have provided over my lifetime have been incredible. Carol Chai, my trusty sidekick, thank you for putting up with the late nights.

Co-Supervisors: Prof. Bjarki Hallgrimsson and Prof. Dr. Troy Anderson, thank you for your endless guidance and making the fieldwork in Uganda a possibility. It was an experience of a lifetime. Without your impromptu meetings, connections, and knowledge, this thesis would not have been a possibility.

School of Industrial Design and the School of Business: Thank you to the Faculty in the School of Industrial Design, Prof. Dr. Thomas Garvey, Prof. Dr. Lois Frankel, Prof. Dr. WonJoon Chung, Prof. Stephen Field, Prof. Chantal Trudel—over the last six years you have been awesome - you have been like a family away from home. Thank you to the Staff in the School of Industrial Design, Valerie Daley, Anna Kim, Walter Zanetti, Terry Flaherty, Jim Dewar, Jennifer Tataryn, and Dysney Hernandez Leyva—your support has been indispensable. Prof. Dr. Ahmed Doha, thank you for being an amazing coach during our research and providing me with a great learning experience. Prof. Dr. Blair Rutherford, thank you for preparing me for my fieldwork.

Peers: In particular Amanda Cox and Alyssa Wongkee, who kindly provided their insights from their fieldwork Uganda. Thank you to Corinna Robitaille, Daniel Bianchi, Hala Hawa, Maria Frangos, Nick Jewkowicz, and Sylvain Després. You have been an awesome cohort. Thank you to the first year Master of Design class. Thank you to all of the students that I taught during my teaching assistantship-you are awesome. Thank you to my editor, Chris Johnson, he has saved everyone who reads this a lot of grief.

Participants: Navin Parekh, Baluku Peter, Bwambale Robert, and Dean Mellway, please let me express my sincerest gratitude for your support in this research. Thank you to all of the people I met in Uganda, Francis and Adrianne Mugwanya and their family, Friday and his technicians, Victor Maliamungu and his technicians, Connie Kekihembo and her family, Dennis Nsimenta and his technicians, and Fred Semakula. Thank you Sharmini and Stefan Constantinescu, Keoke King, Marc Krizack, Dr. Don Schoendorfer, Kerri Jenkins, Natalie Wheeler, and Eric Wunderlich, all of you are doing the most amazing work. Finally, Richard Ilmaso, thank you for driving me to all of my interviews and hotels in Uganda. 


\section{Table of Contents}

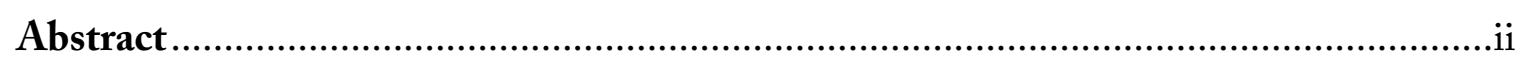

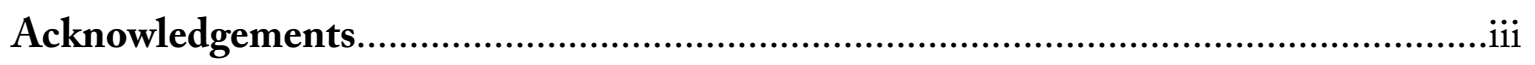

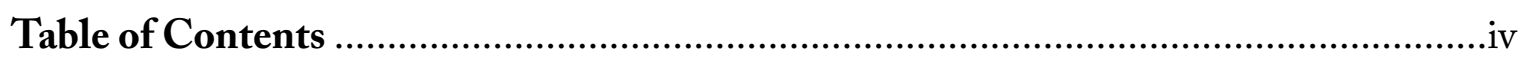

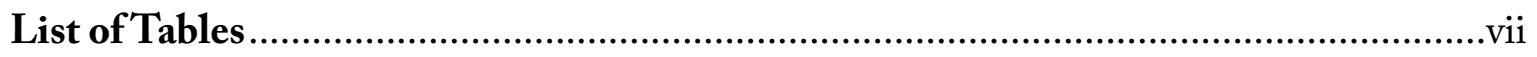

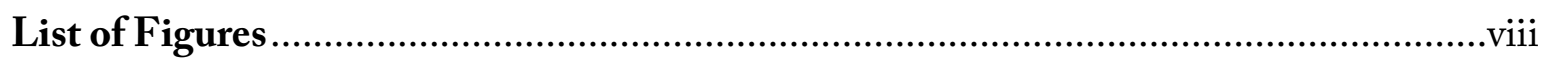

List of Appendices ...................................................................................................

List of Acronyms ...................................................................................................

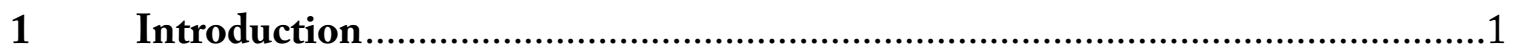

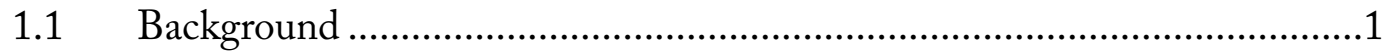

1.2 Purpose

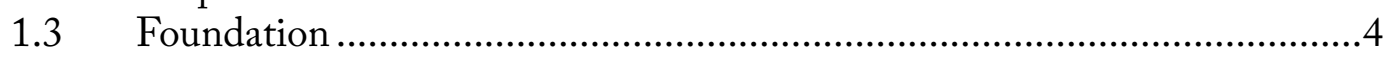

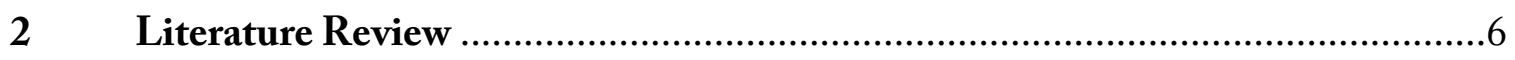

$2.1 \quad$ Effects of Poverty on Disability.................................................................6

2.2 History of Wheelchair Design in Uganda..................................................

2.3 Wheelchair Provision in the Majority World...............................................10

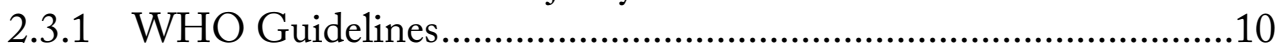

2.3.2 WHO Wheelchair Classification ...................................................12

2.3.2.1 National Small-Scale Production.......................................12

2.3.2.2 National Large-Scale Production..........................................14

2.3.2.3 Imported Used Wheelchairs.................................................15

2.3.2.4 Imported Large-Scale Production ........................................16

2.3.3 Evaluating Wheelchair Alternatives in the Majority World............21

2.4 Wheelchair Provision and Emerging Markets ..............................................22

2.4.1 Imported Large-Scale Production Formal Sector ............................23

2.4.2 National Small-Scale Production Informal Sector ..........................24

2.4.3 Business Model Canvas ....................................................................24

2.4.4 Social Value Propositions.................................................................28

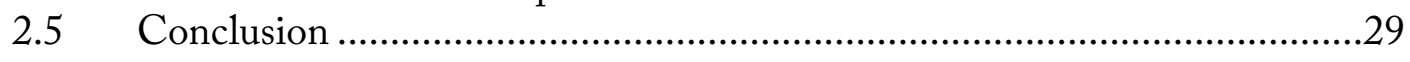




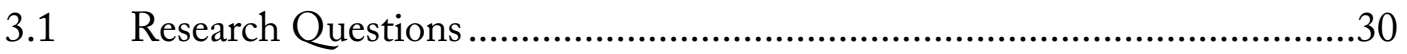

3.1.1 Issue 1: National Small-Scale Production Capacity Building..........31

3.1.2 Issue 2: Imported Large-Scale Production Distribution....................31

3.1.3 Issue 3: Guidelines and Standards .................................................32

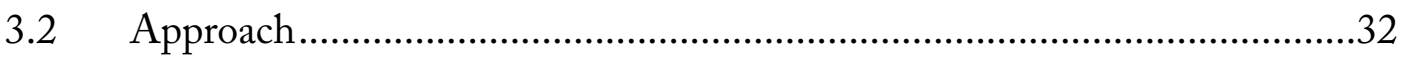

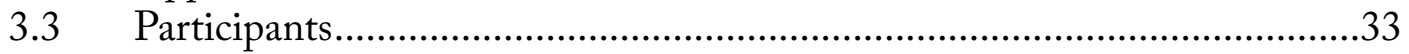

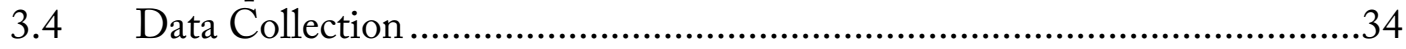

3.4.1 National Small-Scale Production Interview Procedure ....................34

3.4.2 Imported Large-Scale Production Interview Procedure ....................35

3.4.3 Non-Governmental Organization Interview Procedure ....................35

3.4.4 Person with Disability Questionnaire Procedure ...............................35

3.5 Data Processing and Analysis..................................................................36

3.5.1 Audio Recording and Transcription ...............................................36

3.5.2 Analysis Process for Wheelchair Production ....................................36

3.5.3 Analysis Process for Wheelchair Services.........................................37

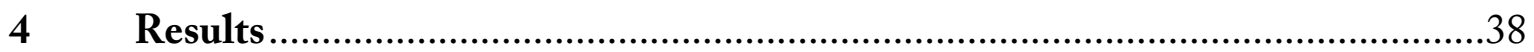

4.1 Business Model Canvas Analyses.................................................................38

4.1.1 National Small-Scale Production Business Model Analysis............38

4.1.2 Imported Large-Scale Production Business Model Analysis ..........42

4.2 National Small-Scale Production ...........................................................45

4.2.1 Workshops....................................................................................45

4.2.2 Wheelchair and/or Tricycle Production..........................................48

4.2.3 Wheelchair and/or Tricycle Prices and Costs ..................................49

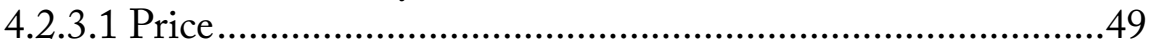

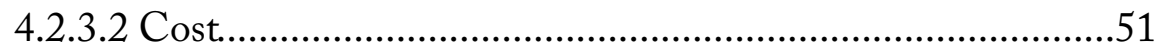

4.2.4 Resources.........................................................................52

4.2.5 Capacity Building.........................................................................53

4.3 Imported Large Scale Production...........................................................56

4.3.1 Formal Manufacturing Sector ……………………......................56

4.3.2 Distribution Channels ...............................................................57

4.3.3 Wheelchair Prices......................................................................59

4.4 Wheelchair Service Delivery ..................................................................60

4.4.1 Assessment and Prescription ...........................................................60

4.4.2 Funding and Ordering.................................................................61

4.4.3 Product Preparation and Fitting......................................................62

4.4.4 User Training.............................................................................63

4.4.5 Follow-Up, Maintenance, and Repairs............................................63 


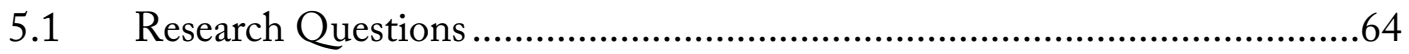

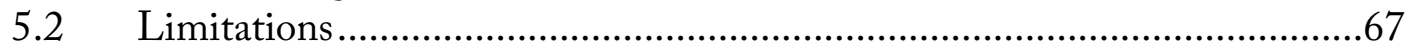

5.2.1 Location and Time.....................................................................67

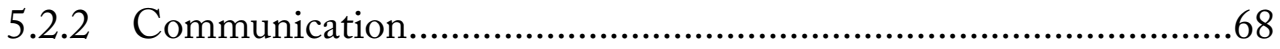

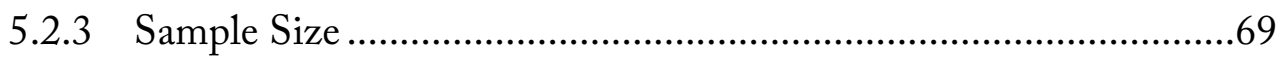

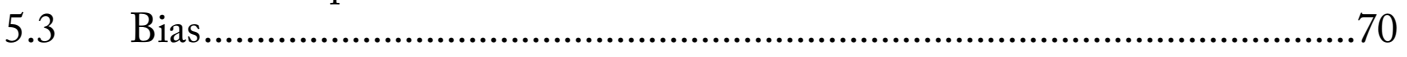

5.4 Recommendations for Organizations Using National Production ...............71

5.4.1 Provide Wheelchair and/or Tricycle Service Training......................71

5.4.2 Provide Production Equipment .......................................................71

5.4.3 Provide Business Training................................................................72

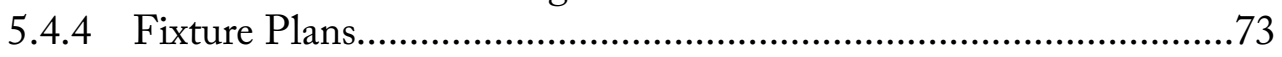

5.4.5 Optimize Tricycle Gearing............................................................73

5.4.6 Perform Trials for Variable Speeds ..................................................74

5.4.7 Increase Wheelchair and Tricycle Offerings.....................................74

5.5 Recommendations for Imported Large-Scale Production............................75

5.5.1 Use Readily Available Spare Parts .................................................75

5.5.2 Engage Communities ...................................................................76

5.6 Future Research and Development...........................................................76

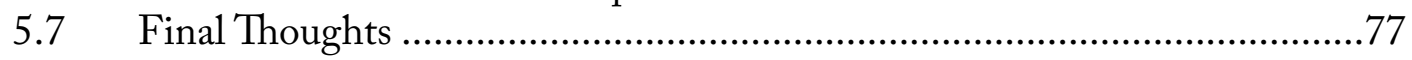

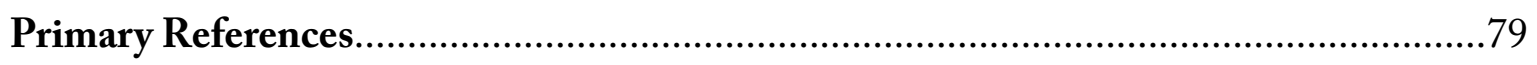

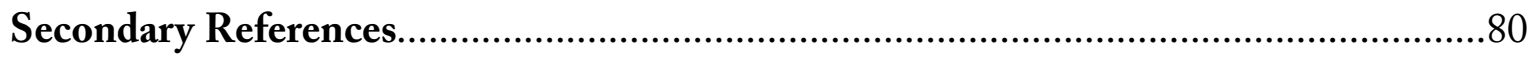

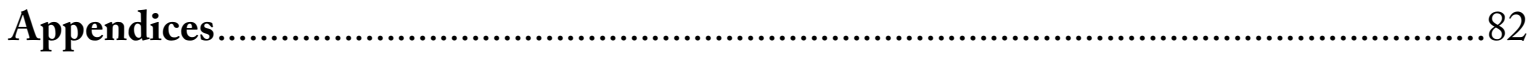

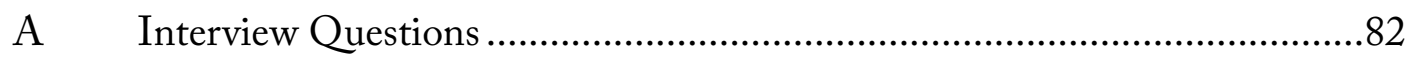

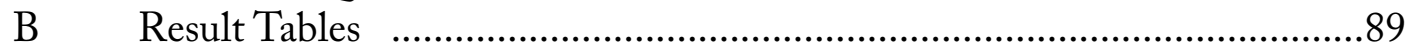

C National Production Part Costs in Kasese..................................................98 


\section{List of Tables}

Table $1 \quad$ Four classifications of wheelchair provision.........................................12

Table 2 Prices of national wheelchairs and tricycles by type................................50

Table 3 Estimated prices of imported wheelchairs landed in Kampala ..................59 


\section{List of Figures}

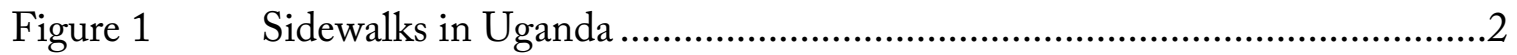

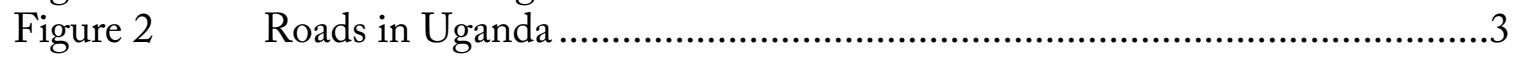

Figure 3 Huckstep wheelchair ............................................................................

Figure 4 Standard dual-sided bicycle hub and modified single-sided bicycle hub....8

Figure $5 \quad$ Hand-operated tricycle.........................................................................

Figure 6 Whirlwind Wheelchair International RoughRider....................................19

Figure $7 \quad$ Motivation Charitable Trust Rough Terrain ..............................................19

Figure 8 United Cerebral Palsy Wheels for Humanity Liberty.................................19

Figure $9 \quad$ Free Wheelchair Mission Gen. 1..............................................................19

Figure 10 Global Research Innovation and Technology Leveraged Freedom Chair....19

Figure 11 Business model canvas...........................................................................25

Figure 12 National small-scale production business model canvas ..............................39

Figure 13 Imported large-scale production business model canvas .............................42

Figure $14 \quad$ Rwenzori Metal Workshop ……………....................................................46

Figure 15 Infrastructure in Kasese, Uganda...............................................................46

Figure 16 Infrastructure in Kampala, Uganda ………...........................................47

Figure 17 Katalemwa Cheshire Home ……………...............................................47

Figure 18 Mulago Orthopaedic Workshop................................................................48

Figure 19 Centre for Disability and Rehabilitation ....................................................48

Figure 20 Tricycle at Mulago Orthopaedic Workshop ................................................49

Figure 21 Huckstep at Mulago Orthopaedic Workshop .............................................49

Figure 22 3-wheeler at Katalemwa Cheshire Home...................................................49

Figure 23 4-wheeler at Katalemwa Cheshire Home....................................................49

Figure $24 \quad$ Hand-assembled forks.......................................................................51

Figure 25 Welding at Rwenzori Metal Workshop....................................................51

Figure 26 Production fixtures at Katalemwa Cheshire Home ...................................55

Figure 27 Break tolerances at Katalemwa Cheshire Home ..........................................55 


\section{List of Appendices}

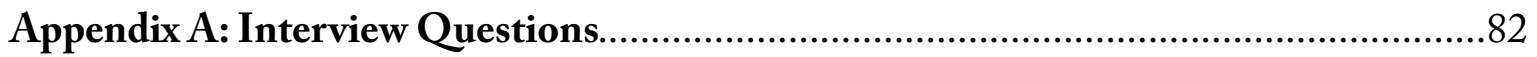

A.1 Sample Questions for National Small-Scale Producers...............................82

A.2 Sample Questions for Imported Large-Scale Producers ...............................84

A.3 Sample Questions for Non-Governmental Organizations...........................85

A.4 Questionnaire for People with Disabilities...................................................86

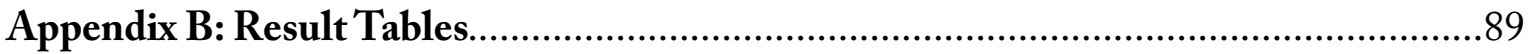

B.1 Result Table for National Small-Scale Producers Results ...........................89

B.2 Result Table for Imported Large-Scale Producers Results...........................99

B.3 Result Table for People with Disabilities......................................................96

Appendix C: National Production Costs in Kasese ......................................................98 


\section{List of Acronyms}

BMC Business Model Canvas

NSSP National Small-Scale Production

NLSP National Large-Scale Production

IUW Imported Used Wheelchairs

ILSP Imported Large-Scale Production

NGO Non-governmental organization

PWDs People with Disabilities

WHO World Health Organization 


\section{$1 \quad$ Introduction}

Considering that poverty affects the majority of the world's population, this literature review refers to the majority world instead of the developing and/or third world, which has a negative connotation (Balaram, 2010).

This research explores wheelchair provision in the majority world with a focus on Uganda as a case study. It addresses three areas that include: 1) national small-scale production (NSSP); 2) imported large-scale production (ILSP); and, 3) wheelchair service-delivery. Design and business methods were used to collect, analyze, and communicate the results of questionnaires, interviews, and observations. This research investigates the limitations of wheelchair provision in Uganda and suggests some alternative approaches that may be explored further by researchers, organizations, or manufacturers. It was completed as part of a Master of Design degree in Industrial Design with a interdisciplinary focus on International Business.

\section{$1.1 \quad$ Background}

People with disabilities (PWDs) represent a substantially underserved population throughout the majority world. In certain areas of Uganda it has been estimated that only a tenth of the population requiring a wheelchair have access to one (Muriska, 2010). Consequently, the remaining population with physical disabilities often use crawling to travel short distances from their homes. While there are several wheelchair options available to this population, these 
technologies are susceptible to a range of design, production, and distribution issues, which impedes the widespread delivery of suitable assistive devices.

PWDs represent one of the poorest populations in Uganda and they are often unable to afford adequate healthcare services (World Bank, 2014; Beattie et al, 2006). This means that the majority of wheelchairs in Uganda are not prescribed, fitted, or suited to the needs and abilities of the wheelchair user. This lack of prescription can result in medical complications, like pressure sores and ulcers that are potentially harmful to PWDs.

Infrastructure in Uganda is frequently inaccessible for PWDs; most sidewalks, doorways, and forms of public transportation do not accommodate wheelchairs (Figure 1; Figure 2). Using a wheelchair is further complicated by the terrain, which consists of rolling hills and mountains, meaning manually-driven wheelchairs become difficult to use over long distances.

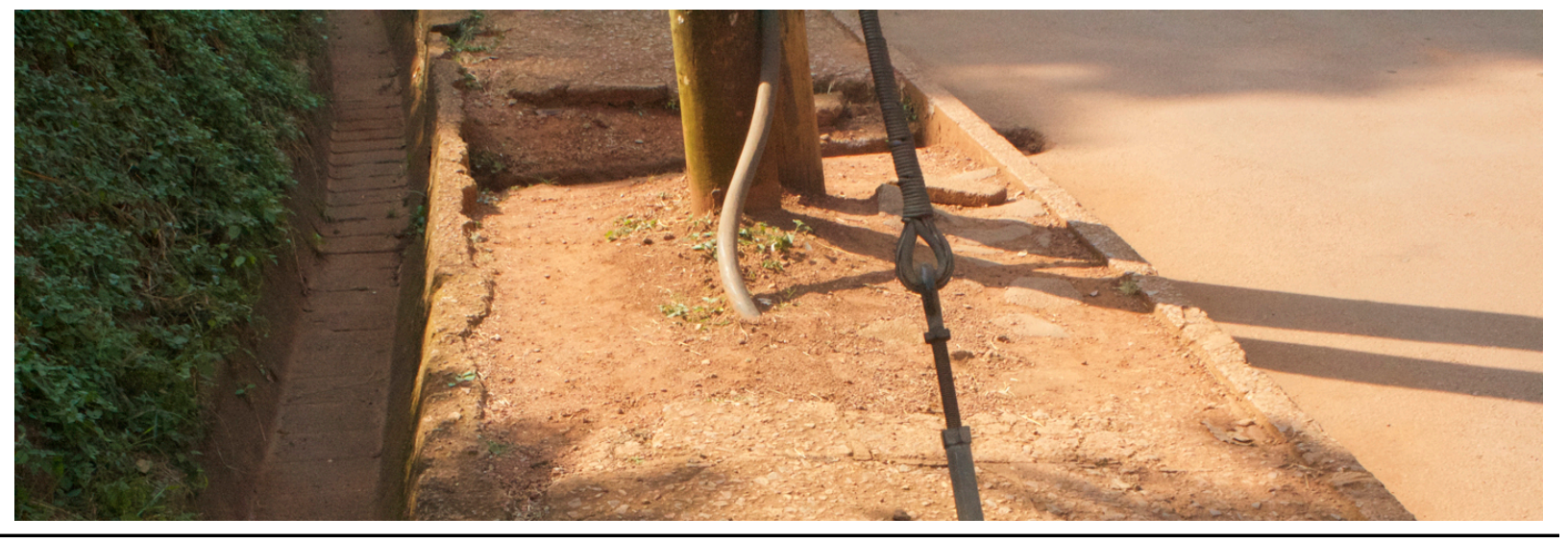

Figure 1 | Sidewalks in Uganda. 


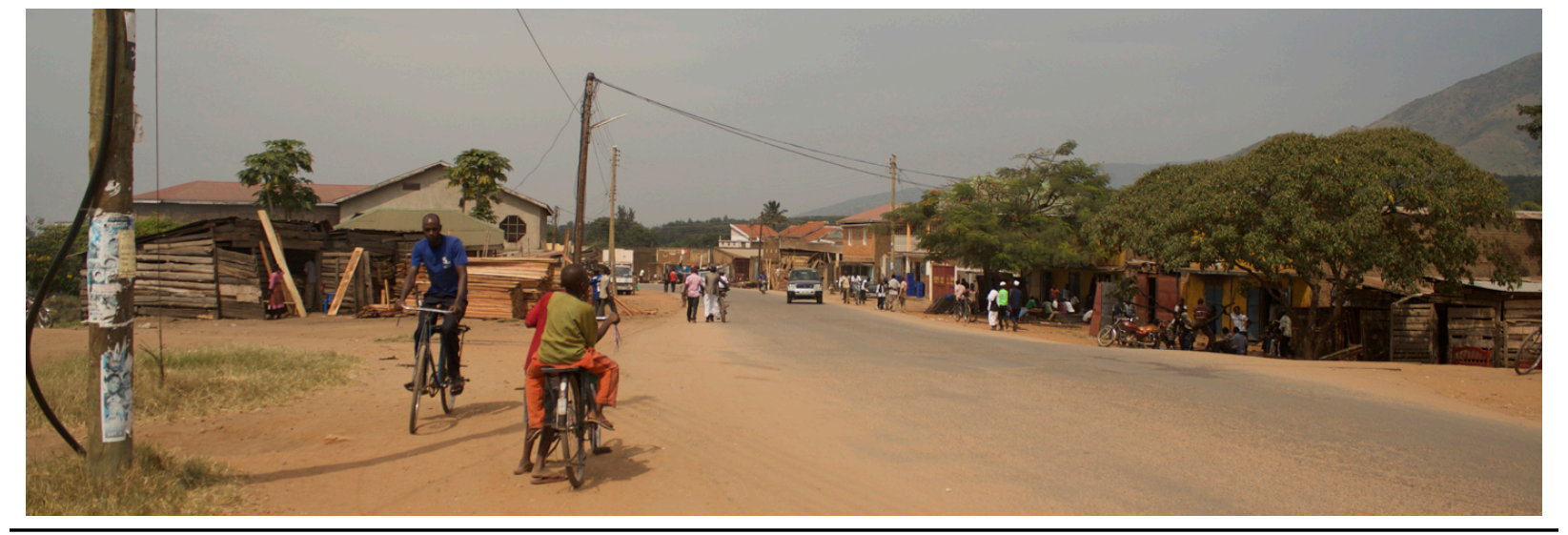

Figure 2 | Roads in Uganda.

\subsection{Purpose}

The purpose of this research is to understand how design, production, and distribution factors have effected the development of wheelchair provision in the majority world. It addresses these limitations because they are critical to the success of widespread wheelchair provision. The production of appropriate wheelchairs have polarized towards NSSP and ILSP in Uganda. These two types of approaches have their own unique limitations. This research concludes that NSSP needs to increase production capacity by addressing standardization, key resources, and business training; and ILSP needs to optimize distribution by addressing micro-logistics and reverselogistics.

This research is intended to document the different methods of provisioning wheelchairs in the majority world. This is particularly important because there are few academic publications that discuss ILSP wheelchair provision. While NSSP have been documented in the past, the research 
on this kind of production is over a decade old. Documentation is needed on the current options for implementing, expanding, and restructuring wheelchair provision strategies.

\section{$1.3 \quad$ Foundation}

This research was based on two previous projects that involved Carleton University's School of Industrial Design and the Sprott School of Business. The first project involved the development of wheelchair technology in Uganda, which was completed by students and faculty from the School of Industrial Design at Carleton University between 2012 and 2014. The second project involved the development of rain water collection systems in Tanzania, which was a completed by students and faculty from the School of Industrial Design, Sprott School of Business, and Faculty of Engineering and Design at Carleton University between 2014 and 2015. These projects formed a foundation for ongoing collaborative efforts between these departments at Carleton University.

Given that the School of Industrial Design had established connections in Uganda for the development of assistive technology, Uganda was a practical choice for the fieldwork in this research assessment. Navin Parekh, founder of the Canada-based organization, CanUgan, has been a partner with the School of Industrial Design for the design and research projects in Uganda. CanUgan works with a Uganda-based organization, the Kasese District Union of Persons with Disabilities (KADUPEDI) to provision tricycles in Kasese, Uganda. Baluku Peter, KADUPEDI Coordinator, and Bwambale Robert, KADUPEDI Treasurer, were integral to this 
research as they distributed questionnaires to PWDs on behalf of the researcher and translated the responses from PWDs. 


\section{$2 \quad$ Literature Review}

This chapter addresses the literature that relates wheelchair provision in the majority world. The purpose of this literature review is to examine the current state of wheelchair provision in the majority world. This literature review is partially based on the World Health Organization (WHO) document, the Guidelines on the Provision of Manual Wheelchairs in Less-Resourced Settings which classifies wheelchair production according to one of the following four categories: National Small Scale Production (NSSP), National Large-Scale Production (NLSP), Imported Used Wheelchairs (IUW) and Imported Large Scale Production (ISLP). Several themes emerged from the literature review, which were focused into research questions. The research questions are described in detail in the Methods chapter of this thesis.

\subsection{The Effects of Poverty on Disability}

When it comes to issues of disability within the majority world, poverty becomes associated with the compromise of a range of key human assets. These assets include environmental health risks, which are further magnified within disabled communities (WHO, 2011). According to the WHO, approximately 15 percent of the world's population has some form of disability (WHO, 2011). The WHO identifies several barriers to healthcare in the majority world including prohibitive costs and a lack of skilled healthcare workers (WHO, 2011). These barriers add to the complexity of accessibility in the majority world. 
There are also many underlying social components to living with a disability that become exaggerated in the context of the majority world. According to the World Bank (2014), people with disabilities (PWDs) as a group are more likely to experience adverse socioeconomic outcomes, making employment a challenge (World Bank, 2014). Without employment, many PWDs are stigmatized in the majority world as being a financial burden on extended family rather than net contributors (Cox, 2014). These social issues add to the complexity of accessibility in the majority world.

\subsection{A History of Wheelchair Design in Uganda}

Uganda was one of the first places in Africa to design and build a wheelchair that was suitable for the rough roads and infrastructure found throughout the continent. Doctor Ronald Lawrie (R.L.) Huckstep introduced a locally-designed wheelchair to Uganda in 1967 (Mukisa, 2008). Huckstep designed the first wheelchair for the majority world at the Mulago Orthopaedic Workshop in Kampala, Uganda (Mukisa, 2008). The Huckstep wheelchair (Figure 3)—also called the Kampala wheelchair-was produced using bicycle parts and simple fabrication techniques. It was designed and built to be affordable, durable, and very serviceable in exchange for a bulky and rigid (i.e. non-folding) frame. Therefore, the Huckstep Wheelchair is not easily used on public transit, small pathways, or indoors (Mukisa, 2008).

A decade after the Huckstep wheelchair was developed, a single-sided bicycle hub became available throughout Uganda (Figure 4)(Mukisa, 2008). It was cored and filled with a solid steel 
axle, which eliminated the need for the exterior frame that usually supports a standard dual-sided bicycle hub. The single-sided bicycle hub has made wheelchairs more mobile and better suited to indoor use.

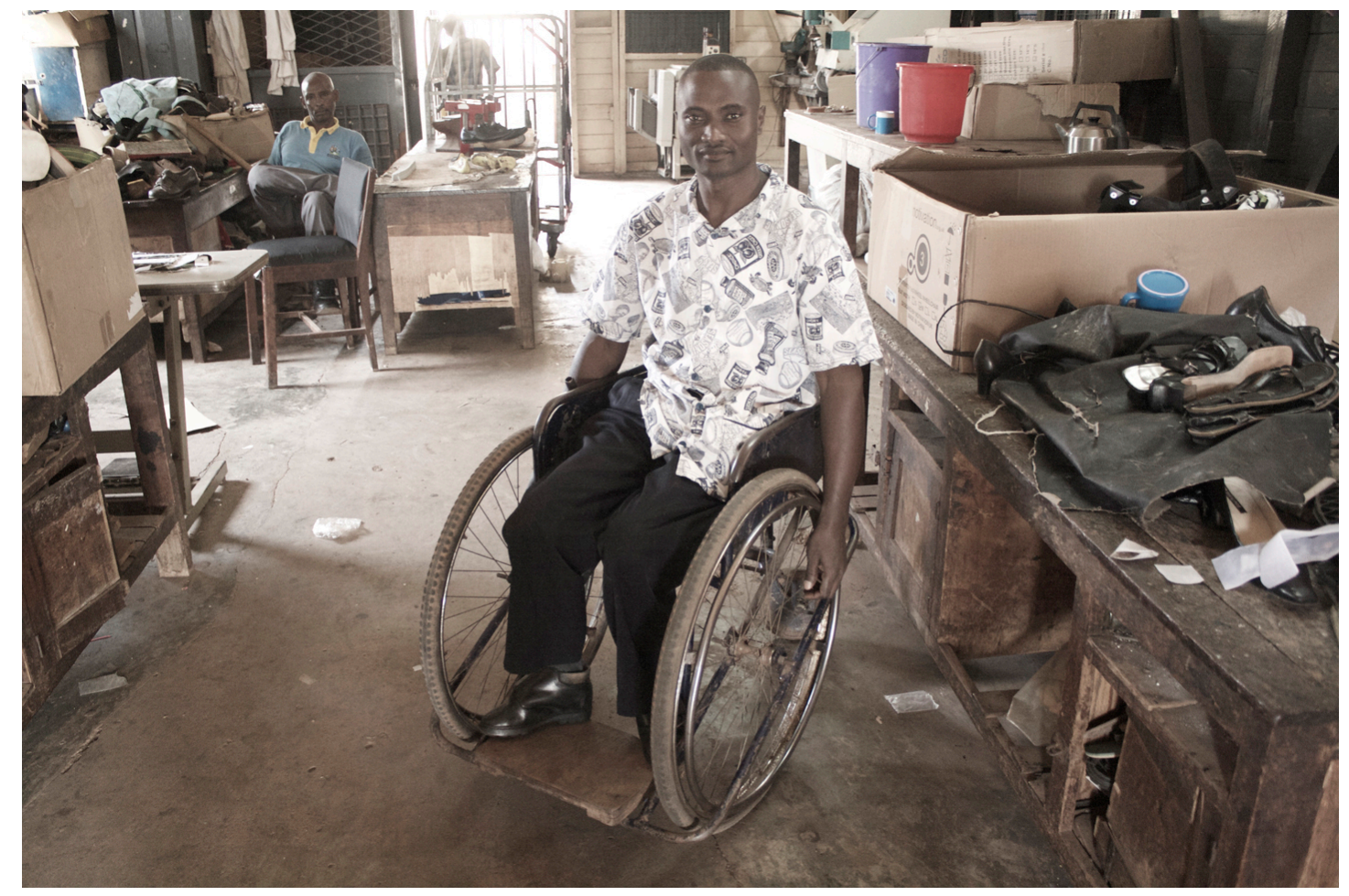

\section{Figure 3 | Huckstep Wheelchair.}

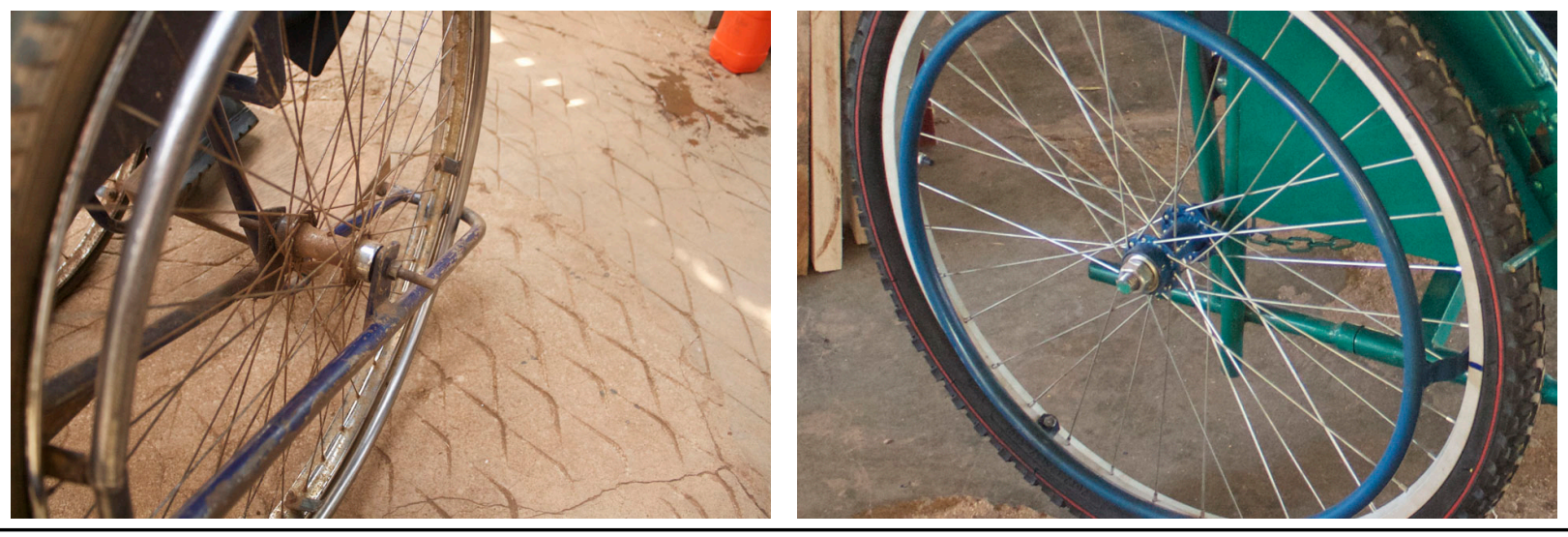

Figure 4 | Standard dual-sided hub (left) and modified single-sided hub (right). 
Hand-operated tricycles were documented shortly after the Huckstep wheelchair was developed. The tricycle (Figure 5) is one of the most successful wheelchair designs produced throughout Africa and Asia for a number of reasons: 1) tricycles have three large wheels that are stable on uneven surfaces; 2) tricycles are larger than wheelchairs, meaning parts require lower tolerances; 3) tricycles can be made from bicycle parts, which are easy to source; and 4) tricycles have gears that make it faster for PWDs to travel long distances.

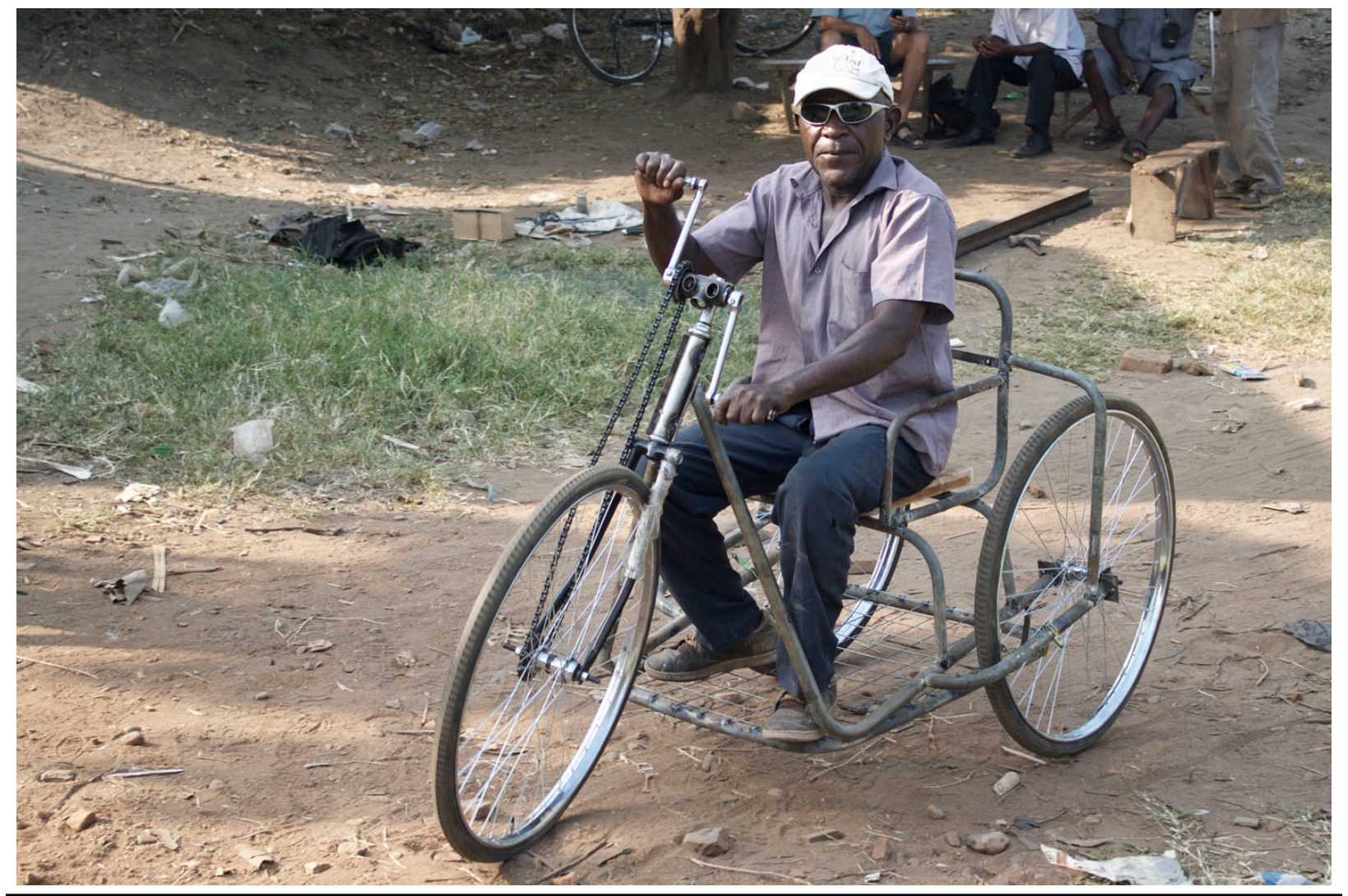

Figure 5 | Hand-operated tricycle. 
The tricycle design has been widely adapted by local producers throughout Africa and Asia (Hallgrimsson, 2013; Winter, 2006). This has lead to certain variants of the tricycle that suffer from several mechanical issues, including inefficient gearing and major stress and failure points within the frame. (Winter, 2006). The School of Industrial Design at Carleton University has been involved in the betterment of the design of tricycles in collaboration with CanUgan. This included a structural evaluation and improved manufacturing approach in 2013 and the identification of using the wheelchair for income generation (Cox, 2014). In addition, the opportunity for a wheelchair and tricycle combination has been explored at the department.

\subsection{Wheelchair Provision in the Majority World}

In recent years, wheelchair provision in the majority world has been addressed by a number international organizations, most notably, the WHO. This section provides an overview of the current state of wheelchair provision in the majority world according to the WHO.

\subsubsection{WHO Guidelines}

The WHO claims that wheelchair provision includes the design, production, and supply of wheelchairs; as well as the wheelchair service-delivery (WHO, 2008). The guideline was developed to increase the efficacy and consistency of wheelchair provision in the majority world.

Adequate wheelchair design ensures that devices are adaptable for a diverse range of PWDs (WHO, 2008). Wheelchair design needs to account for the appropriate seating and postural 
needs of the PWD who is using the device. It is essential that wheelchairs are treated as healthcare products: they must be safe to use, durable for a number of years, and locally serviceable (WHO, 2008).

Wheelchairs can be produced nationally or internationally, but the WHO recommends that they are regulated and standardized by governments (WHO, 2008). The WHO recommends that wheelchairs meet the requirements of the International Organization for Standardization (ISO) 7176 series. The ISO 7176 is the standard for assessing the mechanical properties of wheelchairs, including stability testing and tipping angles (WHO, 2008). Although it was not developed for the conditions of the majority world, the ISO 7176 standard provides a catalyst for organizations to standardize their wheelchairs.

Wheelchair supply refers to the availability of wheelchairs in less-resourced settings (WHO, 2008). This includes the supply of wheelchair-related products (e.g. spare parts).

The WHO claims that the wheelchair service-delivery is as important as the wheelchair itself. The wheelchair service-delivery includes: 1) assessing and prescribing suitable wheelchairs to wheelchair users; 2) securing funding on behalf of wheelchair users; 3) preparing and modifying wheelchairs for use; 4) fitting wheelchairs to wheelchair users; 5) training wheelchair users to safely use and maintain wheelchairs; and, 6) following-up with wheelchair users, providing wheelchair repairs and replacements as necessary (WHO, 2008). The WHO states that it is the responsibility of the organization that is provisioning wheelchairs to replace wheelchairs that are not repairable (WHO, 2008). 


\subsubsection{WHO Wheelchair Classification}

According to the WHO (2008), wheelchairs are typically delivered to the majority world through small-scale national production (NSSP), large-scale national production, imported used wheelchairs (IUW), and imported large-scale production (ILSP)(WHO, 2008). To clarify these alternative forms of wheelchair provision, the four WHO classifications are outlined in Table 1.

Table 1

Four Classifications of Wheelchair Provision

\begin{tabular}{lll}
\multirow{2}{*}{ National } & Small-Scale & Hand-fabricated using basic materials and components \\
\cline { 2 - 3 } & Large-Scale & Mass-produced and distributed regionally \\
\hline \multirow{2}{*}{ Imported } & Used Wheelchairs & Repurposed hospital wheelchairs from Western countries \\
\cline { 2 - 3 } & Large-Scale & Mass-produced and designed for the majority world \\
\hline
\end{tabular}

Note: Adapted from the Guidelines on the Provision of Wheelchairs in Less Resourced Settings (WHO, 2008)

\subsubsection{National Small-Scale Production (NSSP)}

The informal manufacturing sector in the majority world is largely based around small-scale metalworkers. These producers often work with a handful of resources and have very limited and often homemade equipment (King, 1977). Many of these producers are established in a dirt yard near the home of the producer. Given the grassroots nature of these small metalworking businesses, they often learn new techniques with each product developed. Therefore, designs are not standardized, but incrementally improved upon. This iterative process means that wheelchairs 
are often built for a particular user, which has practical benefits in terms of customization, yet these variations mean that there is a lack of standardized parts. While this means that leveraging economies of scale are unfeasible, it is interesting that low-volume production is sometimes beneficial to non-governmental organizations with limited purchasing power. Without preemptive decision making, however, it is noteworthy that producers at this level have very little capability to implement a wheelchair service beyond simply producing the end product.

The greatest tradeoff with the locally produced mobility devices is that the small-scale producers in the informal manufacturing sector do not recognize the need of a wheelchair service. This limited services are further complicated by the lack of representation of wheelchair professionals within healthcare services in the majority world (Beattie et. al, 2006). For this reason, follow-up, maintenance, and repairs have been described as lacking in the majority world. This is evident in the numerous mobility devices that are abandoned outside the homes of their riders because of something as simple as a worn out tire (Winter, 2006). In spite of these provisional issues, designs produced using appropriate technologies thrive in the majority world because of their ingenuity with the available resources at hand. Two local Ugandan designs-namely the Huckstep wheelchair and the hand-operated tricycle- have become two of the most ubiquitous provisions throughout the majority world because of national small-scale manufacturing using locally available materials. 


\subsubsection{National Large-Scale Production (NLSP)}

There is a growing semi-formal manufacturing sector emerging in major cities of sub-Saharan Africa. These sectors are capable of standardization and are capable of higher production capacities than their informal counterparts (Øderud et. al, 2004). When it comes to the national production of assistive devices, organizations in India - like Jaipur Foot—have had success in leveraging the semi-formal sector in the majority world (Jaipur Foot, 2015). However, organizations like Jaipur Foot need to work closely with manufacturers to ensure that the mobility devices are suited to an end user. RoadMaster Cycles, a commercial manufacturer of bicycles in Kampala, Uganda, standardized the hand-operated tricycle and Huckstep wheelchair designs. After RoadMaster Cycles produced a wheelchair design that was too wide for doorways, the company was criticized for lacking a fundamental knowledge of PWDs and assistive devices in general (Øderud et. al, 2004). Therefore, in order to access economies of scale through national factories, organizations that provision assistive devices must be knowledgeable about disabilities in order to guide the factory. Guidelines for the provision of wheelchairs could be very useful to this level of production, where standardization is implemented. Although the need and demand for wheelchairs in sub-Saharan Africa is very high, the economies of scale in a country such as Uganda can not be compared to India. Another organization, Mobility Appliances by Disabled Women Entrepreneurs, attempted to produce a mass produced wheelchair in Uganda, but many obstacles were noted including: a lack of capital, materials, marketing in addition to manufacturing aspects (Mukisa 2008). 


\subsubsection{Imported Used Wheelchairs (IUW)}

One of the most common ways for PWDs to receive a manual wheelchair in the majority world is through a donation from an industrialized country. This method of provision often undermines the environmental, physical, and social needs of the beneficiary. According to Motivation Charitable Trust's program coordinator, Jennifer Howitt, the distribution of donated wheelchairs takes an "anything is better than nothing" approach (Howitt et. al, 2006). This approach often yields inadequate solutions in favour of convenience. Motivation Charitable Trust's operational manager, Sarah Beattie, claims that wheelchairs delivered to low-income countries often lack critical service components in the provisional process (Beattie et. al, 2006). Responding to the provision of wheelchairs in the majority world as medical emergency means that proper provisional services (e.g. assessments and prescriptions) are often overlooked by the need for quick delivery. Several international charity organizations' provisions include these industrialized, yet unsuitable wheelchairs. Beyond the lack of provisional services (e.g. assessment and prescription), donated wheelchairs in less-resourced settings are often unable to function given the state of the roads and infrastructure; these functional factors are further complicated by the need for spare parts, which are often unavailable to local metalworkers (WHO, 2008). These practical factors, paired with the lack of adequate provisional resources, make donated wheelchairs an inadequate solution for the majority world.

The key issue within the charity model of donating is that it often fulfills the needs of the donor before the beneficiary (Beattie et. al, 2006). The problem with this, of course, is that the donations are merely out of convenience. Based on secondary research it seems that the donated 
wheelchairs are unsuitable in all aspects of provision, in terms of prescription, function, serviceability, durability, and comfort (Howitt et. al, 2006; Beattie et. al, 2006; Øderud et. al, 2004). This is precisely what makes donated wheelchairs inappropriate and is why the beneficiaries of wheelchairs must be considered as end users with design requirements, regardless of income.

Given that there are several contextual designs and donated wheelchairs available to PWDs, the issues that surround their provision are relevant and important. The provisional process is integral to the design of all assistive devices and offering a comprehensive approach to delivering wheelchairs is critical to the device's success. According to the WHO, providers of wheelchairs should ensure that each PWD is individually prescribed and fitted for a mobility device that suits their lifestyle, vocation, environment, and physical condition (WHO, 2008). While these

recommendations are laudable, they have yet to be widely implemented in any region. This lack of implementation is evidence of provisional services being described as assumptive and generic (Mukisa, 2008).

\subsubsection{Imported Large-Scale Production (ILSP)}

There are several international organizations that design wheelchairs for the context of the majority world. In 1985, one of these organizations, the California-based Whirlwind Wheelchair International (Whirlwind), published a fabrication manual titled, Independence Through Mobility, which documented the tools, fixtures, and processes necessary to build a ATIHotchkiss wheelchair (Hotchkiss, 1985). This manual was a commendable attempt to establish 
the local production of an international design in the majority world. Since the development of the locally produced ATI-Hotchkiss wheelchair, Whirlwind has switched to manufacturing a new design, the RoughRider, in Asia.

In 1989, two students at the UK-based Royal College of Art, David Constantine and Simon Gue, designed another appropriate wheelchair (Figure 7), which was suitable for the majority world context (Motivation Charitable Trust [Motivation], 2014). The students travelled to Bangladesh where they produced their wheelchair design for an organization in Dhaka. In 1991, the students fundraised in the UK and established Motivation (Motivation, 2014). In recent years, Motivation has moved their wheelchair production to Asia (Constantinescu, 2015).

In 1996, the California-based United Cerebral Palsy Wheels for Humanity (UCP Wheels) started an independent non-governmental organization (NGO) that is run by David Richard (UCP Wheels, 2015). UCP Wheels' mission is to appropriately recycle wheelchairs from the United States in less resourced settings in addition to producing their own designs (Figure 8). UCP Wheels accepts wheelchairs from donors and completely refurbishes them with volunteer labour and donated components from wheelchair companies. UCP Wheels realizes that other wheelchair producers, such as Whirlwind and Motivation, focus on active user wheelchairs, and therefore UCP Wheels focuses on users with more specialized needs, recycling a lot of high quality reclining and tilting space wheelchairs generally used by passive users indoors (UCP Wheels, 2015). 
In 2001, the California-based organization, the Free Wheelchair Mission (FWM) designed the least expensive appropriate wheelchair for the majority world (Figure 9)(FWM, 2015). Don Schoendorfer, a biomedical engineer, founded the FWM when he discovered the substantial need for wheelchairs in the majority world (FWM, 2015). FWM is run by funds from private organizations through individual donations and fundraisers. The FWM designed a wheelchair similar to the Huckstep wheelchair, but the FWM's wheelchair is made from imported materials, including a plastic PVC chair, a steel frame, and standardized bicycle parts. The basic design concept is to assemble a chair on wheels from components already being manufactured in high volumes at low cost. According to Don Schoendorfer, about 900,000 wheelchairs have been shipped by the FWM to 91 different countries since 2001 (Schoendorfer, 2015).

In 2012, the Massachusetts-based startup Global Research Innovation and Technology (GRIT), developed a wheelchair called the Leveraged Freedom Chair, a lever-powered all-terrain wheelchair (Figure 10), for the context of the majority world (GRIT, 2015).

At the turn of the twenty-first century, the development of the large-scale manufacturing sector in Asia caused an advance in production capabilities and volumes. Leveraging economies of scale, this manufacturing sector could make products, including wheelchairs, to a higher degree of quality at a significantly lower cost than local workshops throughout the majority world. As a result of the lower cost of the wheelchairs, international disability organizations, such as The Wheelchair Foundation, purchased large quantities of inappropriate wheelchairs, which they distributed throughout the majority world (Whirlwind, 2012). 


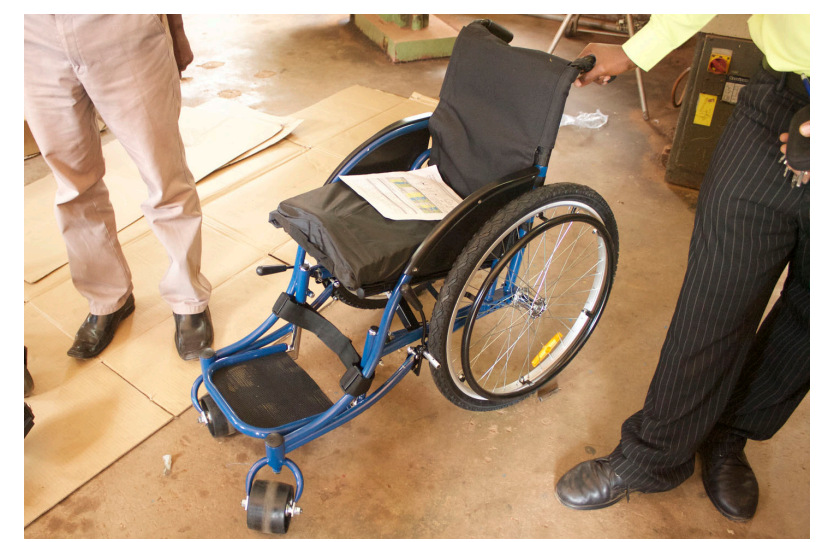

Figure 6 | Whirlwind RoughRider.

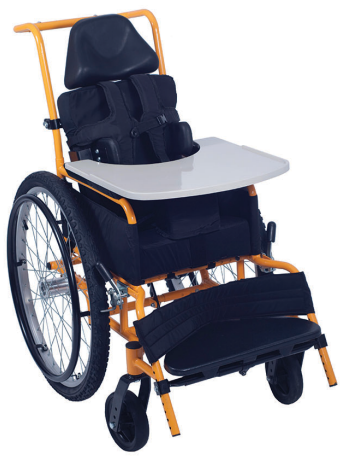

Figure 8 | UCP Wheels Liberty.

Image courtesy of United Cerebral Palsy (2015).

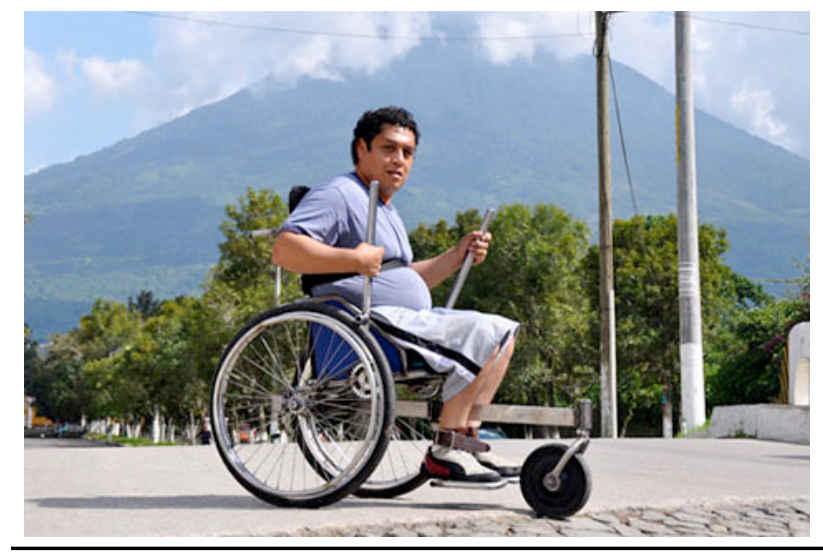

Figure 10 | GRIT Leveraged Freedom Chair.

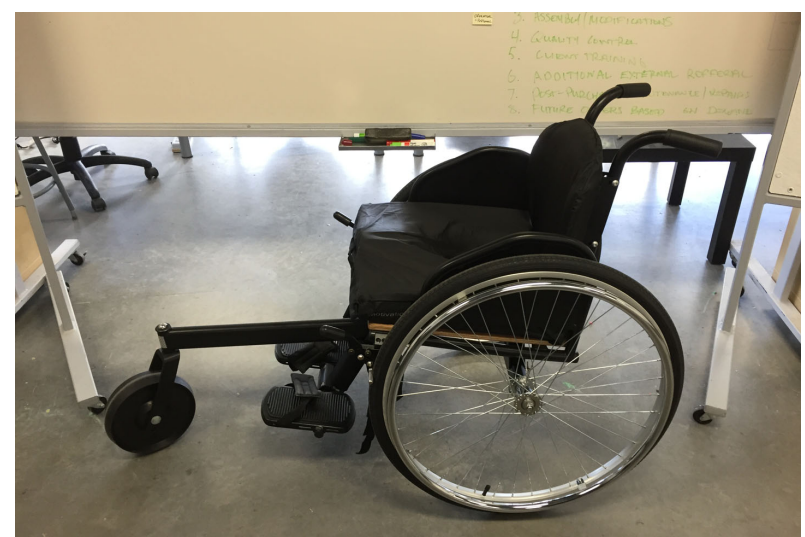

Figure 7 | Motivation Rough Terrain.

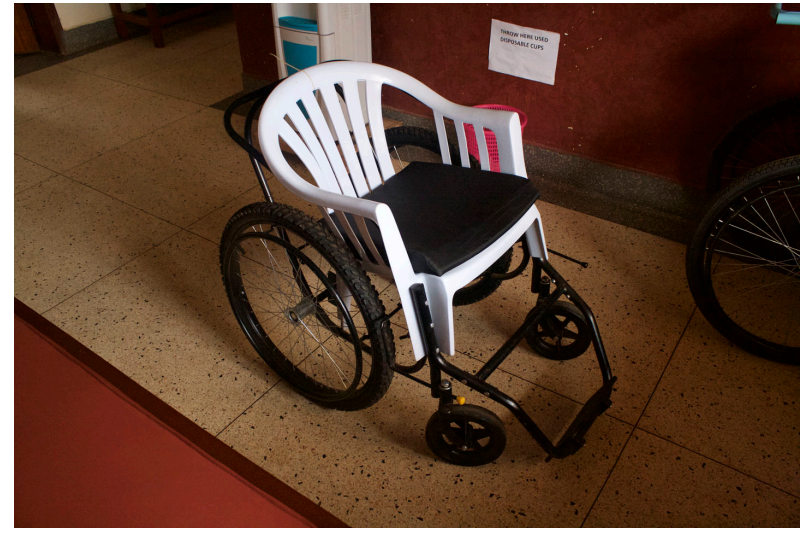

Figure $9 \quad$ FWM Gen. 1.

Image courtesy of MedGadget (2015). 
All of the ILSPs are dedicated to creating manual wheelchairs that maintain the benefits of the locally produced Huckstep (i.e. durability, serviceability and usability) while addressing its tradeoffs (e.g. folding frames, maneuverability, etc.). Another major advantage to the formal sector is that guidelines and standards are implemented and accounted for (WHO, 2008).

Whirlwind, Motivation, UCP Wheels, FWM, and GRIT currently produce wheelchairs offshore and distribute manuals for localized assembly. In 2012, Whirlwind introduced their Wheelchair Provision and Assembly Centers (WPACs), which are intended for entrepreneur and investor franchising at $\$ 127,615$ in start-up capital (Whirlwind, 2012). Wheelchair components are then designed and produced by Whirlwind offshore and imported to the WPAC in the majority world. Upon arrival to the WPAC, wheelchairs are prescribed, assembled, sold, and maintained locally by WPAC personnel (Whirlwind, 2012). According to Whirlwind, WPAC customers include non-governmental organizations, governments, and disabled individuals (Whirlwind, 2012). The WPAC proposition — and other similar propositions from ILSPs-inevitably raise questions about the plausibility of securing investments, creating sustainable distribution channels, and generating revenue from customers with little to no purchasing power.

Given the nature of majority world's infrastructure, the logistics of distribution and shipping is a major barrier in the mass manufactured approach to wheelchair provision. Furthermore, local service facilities are required to have a sizable inventory of spare parts and equipment for repairs. These large inventories have the potential for sunk costs, which are not economically viable for small shops that live hand to mouth. The key strength of international wheelchair producers is their ability to access economies of scale. The fact is that many products can be produced more 
economically and to a higher degree of quality off-shore than within many majority world settings (Hallgrimsson et. al, 2013). However, many non-governmental organizations cannot afford to purchase wheelchairs in large volumes. Landing a mass-produced wheelchair in certain areas of the majority world, consequently, costs more than locally available alternatives. For this reason, any reduction in costs leveraged by mass-production is negated by the costs of distribution. This needs to be addressed if formal manufacturing is a viable option for the provision of wheelchairs in the majority world.

\subsubsection{Evaluating Wheelchair Alternatives}

The reality is that people living in poverty cannot afford locally or mass produced wheelchairs available to meet their mobility needs (World Bank, 2014). This is where donated wheelchairs appear to have merit and likely is why they are imported in the first place. However, simply having a surplus of wheelchairs in industrialized countries does not necessarily make them a viable option in the majority world (Howitt et. al, 2006). Donated wheelchairs that are imported are only suitable for temporary use and flat surfaces, which is uncommon in the majority world.

The formal manufacturing sector in the majority world is capable of producing a large volume of wheelchairs with guidance (Øderud et. al, 2004). The problem with NLSP is that, in large volumes, they compete with the formal manufacturing sector in Asia, which is capable of producing lower priced and higher quality wheelchairs (Hallgrimsson et. al, 2013). 
NSSP and ILSP yields different strengths and weaknesses that are presented in this section of the literature review. In any case, the discussion surrounding these production methods is relevant to the provision of wheelchairs. One on hand, it is clear that NSSP yields several benefits, which include: 1) the ability to readily integrate wheelchair users in the design process (Cox, 2014);2) the ability to advance manufacturing methods and capabilities within a community (Hotchkiss, 1985); and, 3) the ability to stimulate local economies while improving the standard of living for persons with disabilities (WHO, 2008). On the other hand, it is clear that ILSP also yields several different benefits, which include: 1) the ability to professionally design and develop wheelchairs (Whirlwind, 2012); 2) the ability to produce in large volumes and exploit economies of scale (King, 2015); and, 3) the ability to produce wheelchairs more consistently than possible with local production methods (Whirlwind, 2012). Both NSSP and ILSP methods are certainly valid, but an integrated strategy may end up creating the best results. This integrated approach to production could combine some of the ILSP advantages in a way that makes sense for the local context.

\subsection{Wheelchair Provision and Emerging Markets}

This part of the literature review is particularly relevant because it provides a background on developing a business model canvas (BMC), which was used to categorize the primary research data in this research. In the context of this research, BMCs were used to describe the business operations of two wheelchair provision classifications (i.e. NSSP and ILSP). 


\subsubsection{ILSP Formal Sector}

All ILSP wheelchair manufacturers are not-for-profit organizations that operate on funding provided by public and private organizations (Whirlwind, 2012; Motivation, 2015; UCP Wheels, 2015; FWM, 2015; GRIT, 2015). The fact is that wheelchair users cannot afford to purchase their own wheelchair. Therefore, the so-called "market" for wheelchairs in the majority world is not wheelchair users themselves, but public organizations (e.g. the United States Agency for International Development [USAID]) and private organizations (e.g. Latter-Day Saints [LDS]).

All ILSP wheelchair manufactures have issues of logistics and distribution that are relevant to any global organization that is attempting to distribute a physical product on a large scale. Aneel Karnani (2007) points out that distribution, marketing, and exploiting economies of scale is made difficult by culturally diverse and geographically fragmented populations found in less resourced settings (Karnani, 2007). Additionally, effective last mile supply chains are challenged by infrastructure that is often inadequate in remote rural areas.

Similarly, ILSP wheelchair manufacturers require a significant dedication to social responsibility on top of practical issues like distribution, marketing, and funding. ISLPs are providing products to people who are vulnerable consumers as a result of substandard education and illiteracy (Karnani, 2007). ILSP wheelchair manufacturers have a direct responsibility to appropriately label, advertise, and communicate with customers in emerging markets (Jaiswal, 2007). 


\subsubsection{NSSP Informal Sector}

There is a high proportion of private businesses in the majority world that belong to the informal manufacturing sector. During the researcher's fieldwork in Uganda, the informal sector was exemplified by a variety of small businesses that used basic technologies, employed a small number of people, and produced for the surrounding market. According to World Bank (2005), the informal sector is difficult to define as it spans household businesses, micro enterprises, and small enterprises (World Bank, 2005). All of these types of businesses are very different from one another.

According to a study by World Bank (2005) in Uganda, the informal sector faces several constraints, including: 1) limited access to financial resources; 2) limited access to skilled labour; 3) limited access to business education; 4) limited physical resources (e.g. production facilities and equipment); 5) competition from imported products; 6) absence of organized groups (e.g. unions and associations); and, 7) inadequate regulation (World Bank, 2005). These constraints are important because they are common to NSSPs in Uganda.

\subsubsection{Business Model Canvas}

Business models are used to show how organizations create and capture value, describing key information in a way that is intuitively understandable for everyone involved (Osterwalder \& Pigneur, 2009). To effectively generate a business model, organizations use a conceptual framework called the BMC (Figure 11). Having a framework ensures that there is a standard way 
of communicating the different functions of an organization. Given that BMCs describe organizations in detail without oversimplifying information, it makes sense to organize the findings from primary research with NSSPs and ILSPs using a BMC.

There are many different BMCs that have been developed by business theorists; each one is unique, but all of them have the same objective of describing and communicating business models. The collected data in this research project was categorized using the canvas developed and described by Alexander Osterwalder and Yves Pigneur (2009), which is widely accepted as industry standard in the business community (Osterwalder \& Pigneur, 2009). The BMC they developed is suitable for all organizations, including social enterprises and charities.

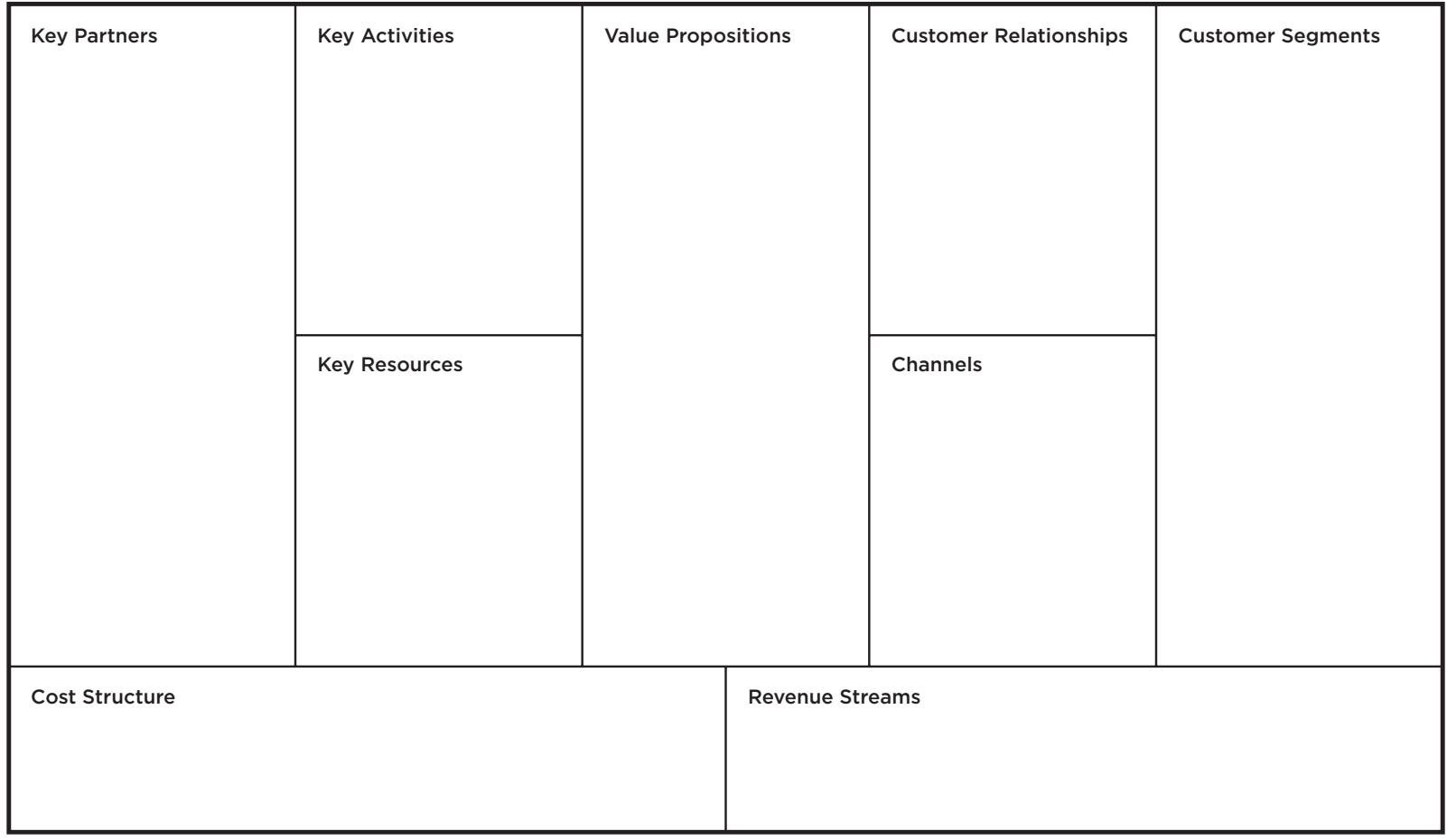

Figure 11 | The BMC which is divided into nine building blocks. Adapted from the Business Model Generation (Osterwalder \& Pigneur, 2009) 
Customers can be specified into one or more distinct segments, each of which has a common set of needs (Osterwalder \& Pigneur, 2009). Organizations must define which customer segments they should serve. There are several types of markets that a business model can sell to: unsegmented mass markets, specialized niche markets, segmented customer groups, unrelated diversified markets, and multi-sided markets (Osterwalder \& Pigneur, 2009). For example, wheelchair producers serve two different niche markets, which include NGOs and PWDs. While PWDs usually do not pay for their wheelchair, they are still considered a customer segment because they derive value from the producer.

Customers segments choose between different organizations based on offerings that solve their needs or problems. These offerings are called value propositions, and they can be either quantitative (e.g. price) or qualitative (e.g. customer experience) (Osterwalder \& Pigneur, 2009). For example, wheelchair producers create social value for NGOs and their supporters by creating wheelchairs and/or tricycles for donation to PWDs.

Channels include elements of communication, distribution, and sales to reach different customer segments (Osterwalder \& Pigneur, 2009). Organizations use channels to deliver value propositions by: 1) making the themselves visible; 2) communicating their offerings; 3) allowing customers to purchase products and/or services; 4) delivering products and/or services to customers; and, 5) performing post-sales support. For example, ISSPs occasionally use regional distributors to deliver their wheelchairs to NGOs and PWDs, while NSSPs use direct sales. 
Organizations need to have clear relationships with their customer segments. The motivation for providing positive customer relationships is customer acquisition, customer retention, and boosting sales (Osterwalder \& Pigneur, 2009). For example, both NSSPs and ILSPs often retain customer segments using personal services such as custom fitting wheelchairs.

Revenue streams capture the value a company creates through offerings to customer segments. All organizations, even charitable ones, require revenue to operate. Revenue streams can have several different structures, including asset sales, usage fees, subscription fees, leasing, licensing, brokerage fees, and advertising (Osterwalder \& Pigneur, 2009). For example, wheelchair producers generate revenue from wheelchair and/or tricycle (i.e. asset) sales to NGOs using a fixed price model.

Key resources allow organizations to create value in terms of products and/or services. Depending on the business model, different key resources are necessary, whether they are physical, financial, intellectual, or human (Osterwalder \& Pigneur, 2009). For example, NSSPs have physical resources (e.g. production equipment, workshops, etc.), because their wheelchairs and/or tricycles are built by hand, these producers require large amount of human resources. ILSPs mainly use intellectual resources, as their wheelchairs are produced under license and distributed through key partnerships.

Key activities are the actions that allow a company to create value, reach markets, and earn revenue (Osterwalder \& Pigneur, 2009). Key activities can include production, problem solving, 
and creating and maintaining platforms. For example, wheelchair producers' key activities include the production and distribution of wheelchairs.

Key partnerships allow organizations to operate more efficiently by acquiring resources and outsourcing activities (Osterwalder \& Pigneur, 2009). For example, wheelchair producers often develop key partnerships with other manufacturers and distributors to reduce their overhead costs.

Business models have a certain cost structures that are involved with creating, delivering, and capturing value. After organizations define their key resources, activities, and partnerships, cost structures are relatively simple to calculate (Osterwalder \& Pigneur, 2009). Organizations incur several costs, which consist of fixed costs (e.g. facilities, salaries, production equipment, etc.) and variable costs (e.g. materials, spare parts, contracted labour, etc.). Cost advantages are gained from economies of scale (e.g. bulk purchasing) and from economies of scope (e.g. using the same distribution channel for multiple different products).

\subsubsection{Social Value Propositions}

Given that wheelchair provision is funded primarily by charitable organizations, it is important to understand social value propositions. One of the most notable ways of quantifying social value propositions is by evaluating and forecasting Social Return on Investment (SROI). The SROI framework is a tool recently developed by the SROI Network and accounts for social, economic, and environmental benefits of an activity (e.g. wheelchair production). While an SROI 
framework was not used in this research, it is quite relevant to the value propositions that are developed in the BMC framework in the Results chapter of this thesis.

\subsection{Conclusion}

Based on the literature review, NLSP and IUW are not viable alternatives at the moment in Uganda (Howitt et. al, 2006; Øderud et. al, 2004). This was substantiated by Sarah Beattie (2006), who criticized imported used wheelchairs as being inappropriate for PWDs as they do not function in the environment of the majority world (Beattie et. al, 2006). NLSP has not been leveraged successfully for the provision of wheelchairs in Uganda (Øderud et. al, 2004). The literature review resolves that four forms of wheelchair provision exist and that one method is particularly inappropriate for the majority world, namely IUW. The other conclusion from literature review is that in the context of Uganda, the prevalent forms of wheelchair provision are NSSP and ISLP. 


\section{$3 \quad$ Methods}

The literature review addressed the current state of wheelchair provision in the majority world and hypothesized that there are two options for improving widespread wheelchair delivery. The first option is to build national small-scale production (NSSP) capacity to increase the standardization, quality, and volume of appropriate wheelchairs that can be produced nationally. The second option is to improve the efficiency of imported large-scale production (ILSP) to access a large market of small-scale non-government organizations (NGOs) that provision wheelchairs to people with disabilities (PWDs) in the majority world. In addition to addressing national and international production of mobility devices, the literature review illustrated the need for adequate healthcare services in the majority world. The research opportunity is to investigate all three provisional components and propose recommendations for nationally produced and imported wheelchairs, as well as wheelchair services. The goal of these recommendations is to allow wheelchair producers and NGOs to better inform and structure their provision strategy so that more PWDs in the majority world can receive a wheelchair that is appropriate to their needs.

\subsection{Research Questions}

While many publications have addressed the state of wheelchair provision in the majority world, none have cross-examined the alternative forms of wheelchair provisioning. The research questions that emerged from the literature review are listed below, along with hypotheses based 
on those questions. The primary qualitative research included a series of questionnaires, interviews, and observations across multiple participant groups.

\subsubsection{Issue 1: NSSP Capacity Building}

Question 1: What are the main barriers that inhibit national small-scale producers (NSSPs) from capacity building?

Hypothesis 1: Many NSSPs in the majority world operate informally as a result of irregular, small-quantity purchase orders from small-scale NGOs with limited buying power. This limitation is what prevents small-scale NSSPs from accessing the economies of scale that is necessary to reduce their operational costs.

\subsubsection{Issue 2: ILSP Distribution}

Question 2: What are the main barriers that inhibit imported large-scale production (ILSP) distribution?

Hypothesis 2: The landed cost of a shipping container in many areas of the majority world is prohibitive for many organizations with a limited buying power. Depending on the area of the majority world, the landed cost can as much as double the cost of the product. In this case, two locally fabricated wheelchairs can be purchased for the price of one globally manufactured wheelchair. 


\subsubsection{Issue 3: Guidelines and Standards}

Question 3: What wheelchair services are offered in the majority world by NSSPs and ILSPs?

Hypothesis 3: The WHO guidelines are one of the only publications that address wheelchair provision in less resourced settings. While it is possible that there is some form of wheelchair service available in the majority world, it is likely that wheelchair services are limited, because access to healthcare is limited.

\subsection{Approach}

The research approach was exploratory and the methodology included an open-ended series of questionnaires, interviews, and observations. The WHO Guidelines on the Provision of Manual Wheelchairs in Less Resourced Settings (WHO, 2008) were used as a framework to design the data collection tools. An exploratory approach was practical because the research questions address broad issues and they do not define a clear problem with wheelchair provision. The qualitative questionnaires, interviews, and observations were intended to allow participants to communicate their individual opinions on wheelchair provision. The researcher comes from an industrial design background and was informed by existing literature prior to designing and conducting the primary research and fieldwork in Uganda. 


\subsection{Participants}

The participant groups chosen for this research were producers, organizations, and wheelchair users. The research on NSSP was conducted in Uganda with national small scale producers (NSSPs), NGOs, and PWDs. The research with these stakeholders was facilitated by the Canada-based NGO, CanUgan and their Uganda-based partner organization, the Kasese District Union of Persons with Disabilities (KADUPEDI). These participant groups were chosen because the School of Industrial Design at Carleton University has connections with these organizations, which meant that logistics were straightforward. The research on imported large scale producers (ILSPs) was conducted through interviews with several organizations who develop and manufacture wheelchairs for the context of the majority world. These manufacturers included Whirlwind Wheelchair International (Whirlwind), Motivation Charitable Trust (Motivation), United Cerebral Palsy Wheels for Humanity (UCP Wheels), and the Free Wheelchair Mission (FWM). Interviews with Motivation were facilitated by Carleton University's Research Education Accessibility and Design (READ) Initiative and the Torontobased international disability NGO, Diversable. While certain connections were made through organizations, many of the interviews with both NSSPs and ILSPs were setup by cold-calling and snowballing. Each interviewed participant was asked if they could forward the researcher to other relevant participants.

An effort was made to investigate wheelchair provision in a way that accurately represents Uganda and, to an extent, the majority world. Multiple participant groups were identified and chosen in order to gain different insights and perspectives on wheelchair provision. The fieldwork 
in Uganda was conducted in a rural setting (Kasese, Uganda) and an urban setting (Kampala, Uganda). The fieldwork was conducted over a ten-day period, which made visiting other areas of Uganda impractical. The fieldwork in Uganda exposed the researcher first-hand to the majority world environment, which helped the researcher to develop a contextual appreciation. The fieldwork was also important to represent the different methods of provisioning wheelchairs in the majority world, which was one of many reasons for interviewing both NSSPs and ILSPs. Some information on NSSPs was provided by ILSPs who had previously produced wheelchairs within the majority world.

\subsection{Data Collection}

\subsubsection{NSSP Interview Procedure}

NSSP interviews and workshop observations were conducted in Kasese and Kampala. The author used a pre-determined, semi-structured interview to inquire how NSSPs view the national issues of wheelchair provision (Marshall, 2006). A series of open-ended questions and probing questions were used to facilitate discussions with NSSPs. Interviews with NSSPs were approximately 30 minutes in length. These interviews, in combination with observations, were chosen by the researcher to gain an understanding of the activities carried-out in the national production and distribution of wheelchairs. Observations captured by photographs and field notes were used to systematically document concrete descriptions of NSSP processes and information about the wheelchairs that they produced (Marshall, 2006). See Appendix A.1 for NSSP interview sample questions. 


\subsubsection{ILSP Interview Procedure}

ILSP interviews were conducted from Canada, over Skype or by telephone, with ILSPs that were located in Canada, the USA, and the UK. A different pre-determined and semi-structured interview was used to gain ILSP perspective on issues of wheelchair provision. These interviews issues spanned both NSSP and ILSP challenges, because many ILSPs have worked with NSSP in the past. Interviews were between 30 and 60 minutes in length, and were transcribed from an audio recording. See Appendix A.2 for ILSP interview sample questions.

\subsubsection{NGO Interview Procedure}

NGO interviews were conducted from Canada, in person or over Skype, and in Kasese and Kampala in person. A different pre-determined and semi-structured interview was used to gain NGO perspective on issues of wheelchair provision (Marshall, 2006). The primary purpose of these interviews was to determine how wheelchairs are being provided to PWDs and understand the interactions of NGOs with either NSSPs or ILSPs, or both. Interviews were between 30 and 60 minutes in length, and were transcribed from an audio recording. See Appendix A.3 for NGO interview sample questions.

\subsubsection{PWD Questionnaire Procedure}

A questionnaire was distributed to five PWDs who had previously received a hand-operated tricycle from CanUgan and KADUPEDI. The purpose of these questionnaires were to determine 
common repairs and issues related to hand-operated tricycles that could potentially be addressed by organizations and NSSPs. Given that the sample of PWDs were not native English speakers, the questionnaire was administered by KADUPEDI in the local language, and a volunteer recorded the responses and returned them to the author. See Appendix A.4 for PWD questionnaires.

\subsection{Data Processing and Analysis}

\subsubsection{Audio Recording and Transcription}

All collected data was audio-recorded and manually transcribed where practical. Transcriptions were edited to omit speech hesitations and grammatical errors. Audio-recording NSSP interviews were not practical because NSSP workshops tend to have a lot of background noise. NSSP interview minutes were recorded by the researcher and reviewed with the NSSP. All of the research results in this dissertation have been approved for publishing by the participants. Participants did not request anonymity and were aware that results would be attributed.

\subsubsection{Analysis Process for Wheelchair Production}

The business model canvas was developed by Osterwalder \& Pigneur (2009), a business theorist, for quickly analyzing the components of an organization. All NSSP and ILSP interviews and observations were coded into key points, which were categorized using a business model canvas 
(BMC) as a framework (Osterwalder \& Pigneur, 2009). For practical purposes, two separate business model canvases were developed, one for NSSP and one for ILSP.

\subsubsection{Analysis Process for Wheelchair Services}

Data from NSSPs, ILSPs, NGOs, and PWDs was coded into key points, which were categorized using the WHO Guidelines on the Provision of Manual Wheelchairs in Less Resourced Settings (WHO, 2008). The categories included: 1) assessing and prescribing suitable wheelchairs to wheelchair users; 2) securing funding on behalf of wheelchair users; 3) preparing and modifying wheelchairs for use; 4) fitting wheelchairs to wheelchair users; 5) training wheelchair users to safely use and maintain wheelchairs; and, 6) following-up with wheelchair users, providing wheelchair repairs and replacements as necessary (WHO, 2008). 


\section{$4 \quad$ Results}

The results were analyzed using the business model canvas (BMC) developed by Osterwalder \& Pigneur (2009) and synthesized using the World Health Organization (WHO) Guidelines on the Provision of Manual Wheelchairs in Less-Resourced Settings (WHO, 2008; Osterwalder \& Pigneur, 2009). Section 1 details the BMC analysis for national small scale production (NSSP) and imported large scale production (ILSP) separately. Section 2 reports the results from interviews with NSSPs in Uganda and observations made at their workshops. This section addresses issues of design, production, and supply at the local level. Section 3 reports the results from interviews with ILSPs who produce wheelchairs for the majority world, including Uganda. This section addresses issues of design, production, and supply at the global level. Section 4 reports the results from interviews with people with disabilities (PWDs), non-governmental organizations (NGO)s, NSSPs, and ILSPs. This section addresses issues of service-delivery in the majority world, including Uganda.

\subsection{BMC Analyses}

\subsubsection{NSSP BMC Analysis}

Figure 12 provides an analysis of NSSPs interview transcripts and observations using the BMC developed by Osterwalder \& Pigneur (2009) as a frame of reference (Osterwalder \& Pigneur, 2009). Given that BMCs tend to be high level, the following describes each category of the 
NSSP BMC in detail. It is important to understand that NSSPs are a part of the informal sector in the majority world, which means that the NSSP BMC varies depending on the individual producer. Therefore, this NSSP BMC (Figure 12) is representative of producer tendencies, which will require further quantitative data to validate.

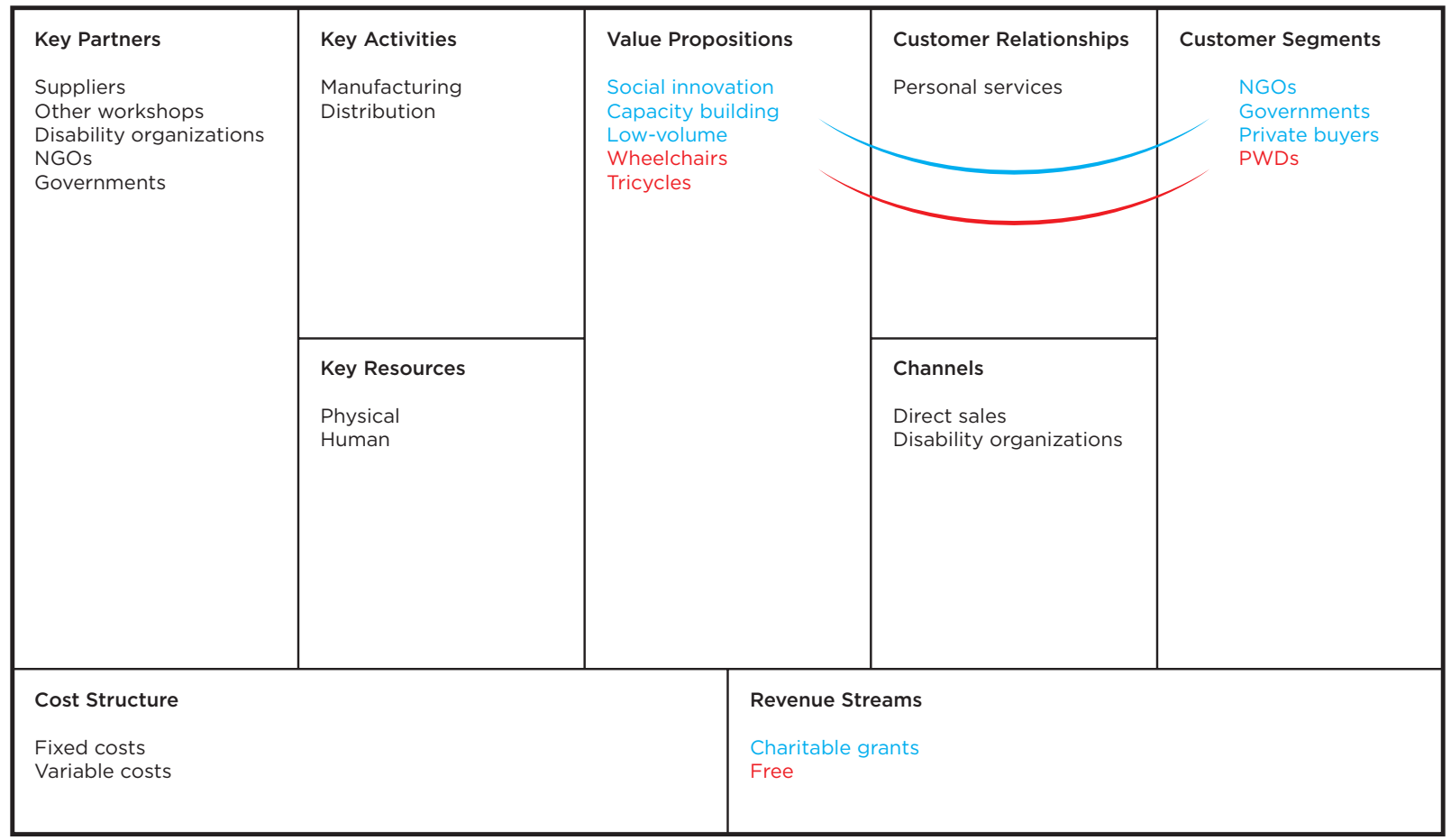

Figure 12 | NSSP BMC

NSSP customer segments can be divided into a paying customer segment (i.e. NGOs, governments, and private buyers) and a non-paying customer segment (i.e. PWDs). The nonpaying customer segment was included in the BMC because they derive value from NSSPs. Furthermore, NSSPs could not deliver value to their paying customer segments without the nonpaying customer segment. NSSPs, NGOs, and ILSPs reported that the largest paying customer 
segments for NSSPs are small-scale NGOs (Maliamungu, 2015; Parekh, 2015; Constantinescu, 2015).

NSSPs offer a few different value propositions: 1) a number of NSSPs, NGOs, and ILSPs stated that NSSP paying customer segments receive benefits in the form of social innovation and capacity building (Maliamungu, 2015; Semakula, 2015; Parekh, 2015); 2) small-scale NGOs have the ability to order in low volumes from NSSPs; and, 3) PWDs reported that they receive value in the form of a wheelchair or tricycle, which gives them independence in their community (Bahumika, 2015; Kaijuba, 2015; Biira, 2015; Baluku, 2015; Bwambale, 2015).

It was observed that NSSPs do not use formal channels. They tend to be contacted by their paying customer segments and subsequently provide their products to PWDs directly. It was reported that a disability organization will only occasionally connect a NGO to a NSSP (Baluku, 2015; Bwambale, 2015; Parekh, 2015).

NSSP customer relationships are highly personal. Observations as well as interviews with NSSPs and NGOs made it clear that NSSPs were keen to work with each individual PWD, often modifying wheelchairs and/or tricycles to suit their educational and employment needs (Maliamungu, 2015; Nsimenta, 2015; Semakula, 2015; Kekihembo, 2015; Parekh, 2015; Krizack, 2015).

All NSSPs reported that they capture value through charitable grants provided by their paying customer segments (Maliamungu, 2015; Nsimenta, 2015; Friday, 2015). One NSSP, the 
Rwenzori Metal Workshop (Rwenzori), produced diversified metal products (e.g. windows, doors, etc.) to supplement their income from tricycle production (Friday, 2015).

Based on observations and interviews with NSSPs, human resources and physical resources make up a major component of national wheelchair production (Maliamungu, 2015; Nsimenta, 2015; Friday, 2015). During the fieldwork in Uganda it was observed that all wheelchairs and tricycles are built by hand and from scratch, which meant that the visited NSSPs required a high proportion of semi-skilled labour. NSSPs reported that their physical resources include workshops and production equipment. (Maliamungu, 2015; Nsimenta, 2015; Semakula, 2015; Kekihembo, 2015).

All of the visited NSSPs carry out several key activities. They manufacture, distribute, and sometimes service their wheelchairs and/or tricycles (Maliamungu, 2015; Nsimenta, 2015; Friday, 2015; Kekihembo, 2015).

Based on observations and interviews with NSSPs and NGOs, NSSPs depend on several key partners, which include suppliers (e.g. local bicycle and hardware shops), other workshops that specialize in different activities (e.g. wood and upholstery shops), and other organizations (e.g. disability organizations, NGOs, and governments)(Maliamungu, 2015; Nsimenta, 2015; Semakula, 2015; Kekihembo, 2015; Parekh, 2015).

NSSPs reported that they have both fixed costs (i.e. facilities, production equipment, and staff) and variable costs (i.e. raw materials and bicycle parts). They pointed out that access to economies 
of scale and scope were not feasible given their limited ability to purchase wholesale

(Maliamungu, 2015; Nsimenta, 2015; Semakula, 2015; Kekihembo, 2015).

\subsubsection{The ILSP BMC Analysis}

Figure 13 provides an analysis of ILSPs interview transcripts using the BMC developed by Osterwalder \& Pigneur (2009) as a frame of reference (Osterwalder \& Pigneur, 2009). Given that BMCs tend to be high level, the following describes each category of the ILSP BMC in detail.

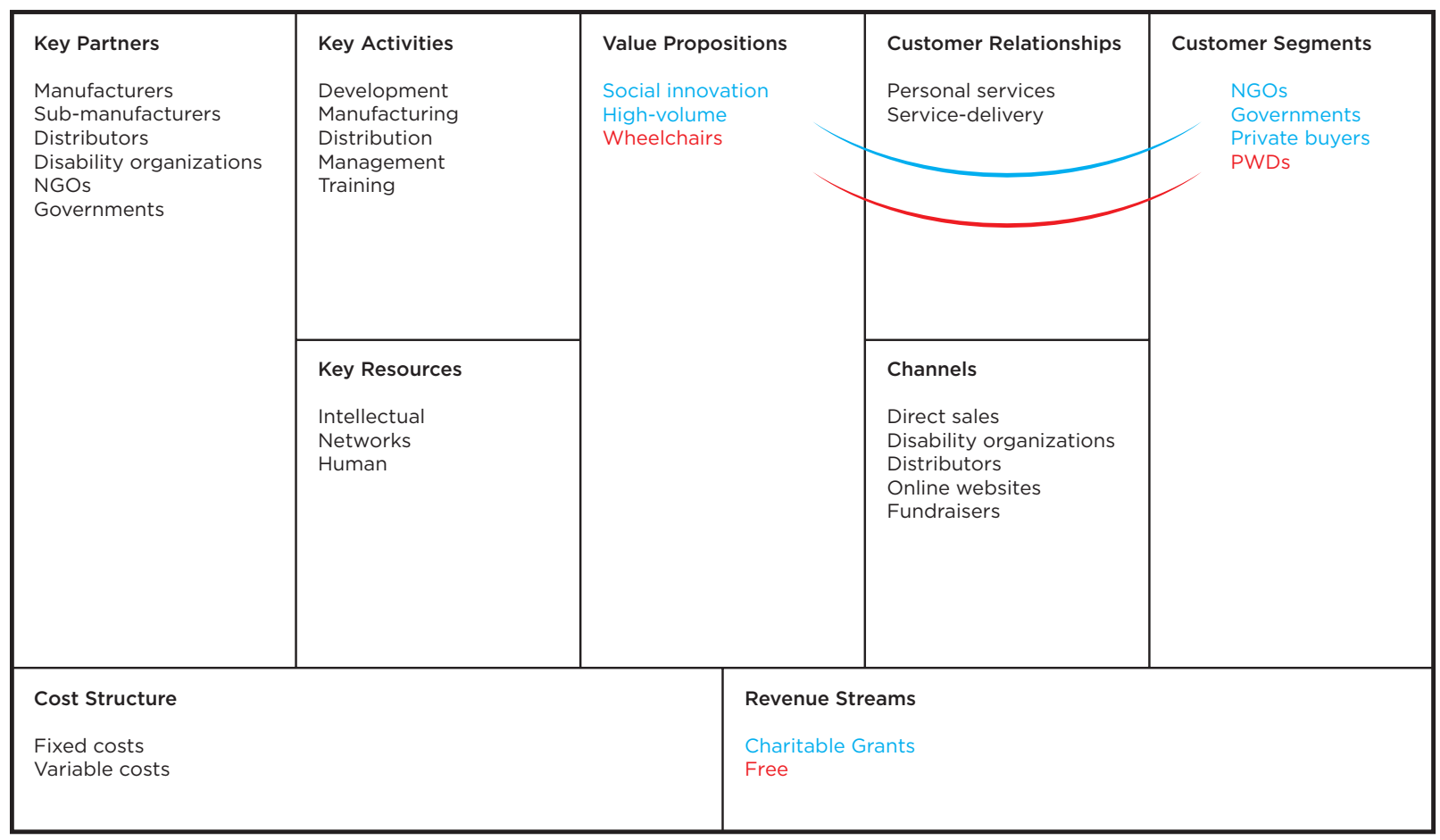

Figure 13 | ILSP BMC 
Similar to NSSP customer segments, ISLP customer segments include a paying customer segment (i.e. NGOs, governments, and private buyers) and a non-paying customer segment (i.e. PWDs). The difference is that their paying customer segment tends to be made up of large-scale organizations that have the ability to purchase large volume orders (Krizack, 2015; Constantinescu, 2015; King, 2015). These large volume orders are necessary because ILSPs usually ship in containers that can hold between 300 and 550 wheelchairs (Constantinescu, 2015; King, 2015; Schoendorfer, 2015).

ILSPs have a number of different value propositions. While they share the benefit of social innovation with NSSPs, their ability to supply large-volume orders and their ability to provide standardized, high-quality products differentiates ILSPs from NSSPs (Krizack, 2015; Constantinescu, 2015; King, 2015; Schoendorfer, 2015). PWDs receive value from ILSPs in the form of an appropriate wheelchair that is suitable for their needs (Constantinescu, 2015; King, 2015).

ILSPs use several different kinds of channels to reach their customer segments. They use fundraisers and websites to raise awareness and capture value directly from their paying customer segment (Krizack, 2015; Constantinescu, 2015; King, 2015). They also use distributors-which consist of regional distribution centres and NGOs—-to provision their wheelchairs to PWDs (Krizack, 2015; Constantinescu, 2015; King, 2015; Schoendorfer, 2015).

Like NSSPs, ILSPs have customer relationships that are highly personal. ILSPs and NGOs reported that ILSPs provide service-delivery training to their paying customer segments so that 
PWDs can receive a wheelchair that is appropriate to their needs (Mugwanya, 2015; Krizack, 2015; Constantinescu, 2015; King, 2015; Schoendorfer, 2015). This service-delivery also ensures that their non-paying customer segment is adequately trained to use their wheelchair appropriately (Constantinescu, 2015). In addition to wheelchairs and wheelchair services, Motivation reported that community engagement projects are facilitated to promote access (Semakula, 2015).

ILSPs reported that they generate revenue from public and private charitable grants (Krizack, 2015; Constantinescu, 2015; King, 2015; Schoendorfer, 2015).

ILSPs have several key resources that allow them to deliver value to their customer segments. These resources include: 1 ) wheelchair designs that are licensed to sub-contracted manufacturers (Krizack, 2015; Constantinescu, 2015); 2) distribution networks and partners that allow them to efficiently ship their wheelchairs (Krizack, 2015; Constantinescu, 2015; King, 2015; Schoendorfer, 2015); and, 3) human resources that allow them to implement their servicedelivery (Krizack, 2015; Constantinescu, 2015).

ILSPs perform several key activities including the development of wheelchairs, sub-contracting manufacturing (e.g. negotiating timelines, controlling quality, etc.), distributing products, managing the organization across multiple continents, and service-delivery training (Krizack, 2015; Constantinescu, 2015; King, 2015; Schoendorfer, 2015). 
ILSP key partners include their sub-contracted manufacturers and their suppliers (Krizack, 2015; Constantinescu, 2015; King, 2015; Schoendorfer, 2015). ILSPs also rely on a network of distributors made up of disability organizations, NGOs, and governments.

ILSPs reported that they have both fixed costs (i.e. offices and staff) and variable costs (i.e. manufacturing and distribution). ILSPs also reported that their ability to access economies and scope highly depends on the quantity of wheelchairs being manufactured in a given production run (Constantinescu, 2015).

\subsection{National Small-Scale Production}

\subsubsection{Workshops}

It is relevant to discuss the workshops, or the environment and context in which local fabrication takes place. After each NSSP was interviewed, observations were made at their workshop. These observations provided an invaluable understanding of what it is like to build wheelchairs and tricycles in less-resourced settings.

The fieldwork involved a visit to the Rwenzori Metal Workshop (Figure 14)(Rwenzori), which is located in the rural village of Kasese (Figure 15). It was observed that products are manufactured in a dirt field using only a handful of resources (Observation, 2015). Rwenzori is operated by a master metalworker, Friday, and his employees, four metalworkers, which includes three apprentices and another master metalworker (Friday, 2015). The primary source of income for the 
workshop comes from manufacturing a variety of metal products (e.g. windows and doors) (Friday, 2015). Building assistive devices exclusively is not economically sustainable in Kasese. The Rwenzori takes an artisan approach to manufacturing tricycles, where each one is built by hand (Observation, 2015). This one-off approach has benefits in terms of customizing the tricycle to the user, but it also limits the manufacturing consistency of tricycles (Observation, 2015). Rwenzori produces approximately three tricycles per month (Friday, 2015).

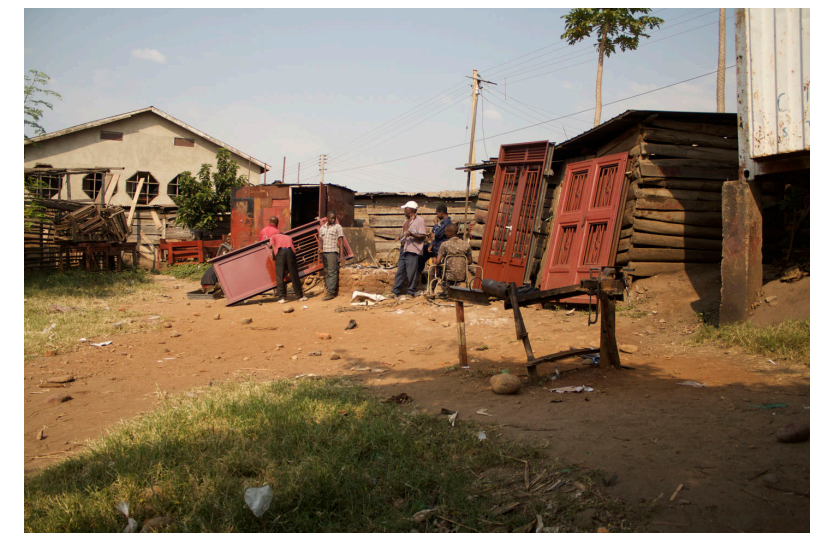

Figure 14 | Rwenzori.

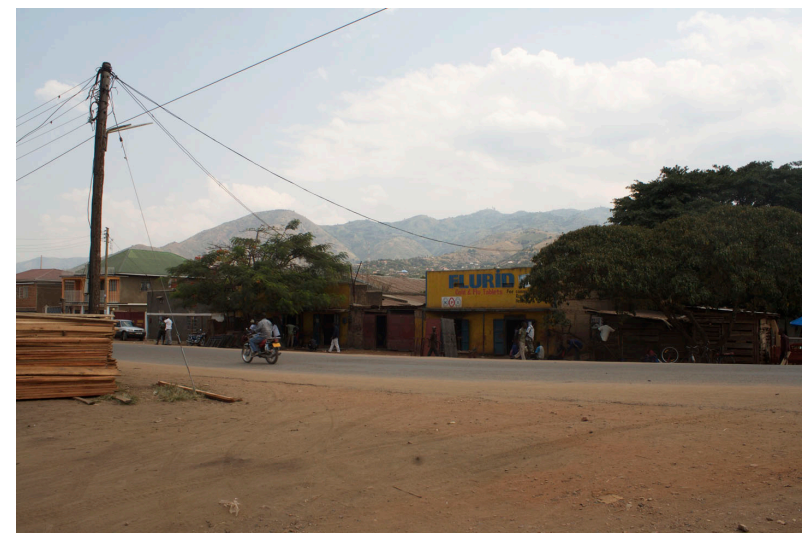

Figure 15 | Infrastructure in Kasese, UG.

The fieldwork also involved visiting several workshops in Kampala (Figure 16), which included the Katalemwa Cheshire Home (Figure 17)(Katalemwa), the Mulago Orthopaedic Workshop (Figure 18)(Mulago), and the Centre for Disability and Rehabilitation (Figure 19)(CDR). The visited workshops are attached to either hospitals or rehabilitation centres, which has practical benefits in terms of the services offered to PWDs (Maliamungu, 2015; Nsimenta, 2015; Kekihembo, 2015). Each of the visited workshops employed between nine and twelve skilled staff, the majority of whom are trained as orthopaedic technologists or a skilled-trades workers 
(Maliamungu, 2015; Nsimenta, 2015; Kekihembo, 2015). Given the significant need for assistive devices in Kampala, all of the visited manufacturers built assistive devices exclusively, including products like walkers, supportive seats, and prosthetics (Maliamungu, 2015; Nsimenta, 2015; Kekihembo, 2015). These manufacturers were relatively well-equipped in comparison to Rwenzori, yet all of the workshops commented that their equipment was operational but outdated, with some machines being as old as forty-years (Observations, 2015; Maliamungu, 2015; Nsimenta, 2015; Kekihembo, 2015). Each manufacturer in Kampala produces approximately twenty wheelchairs per month, but all of the visited manufacturers' pointed out that their production volume varies based on available funding (Maliamungu, 2015; Nsimenta, 2015; Kekihembo, 2015).
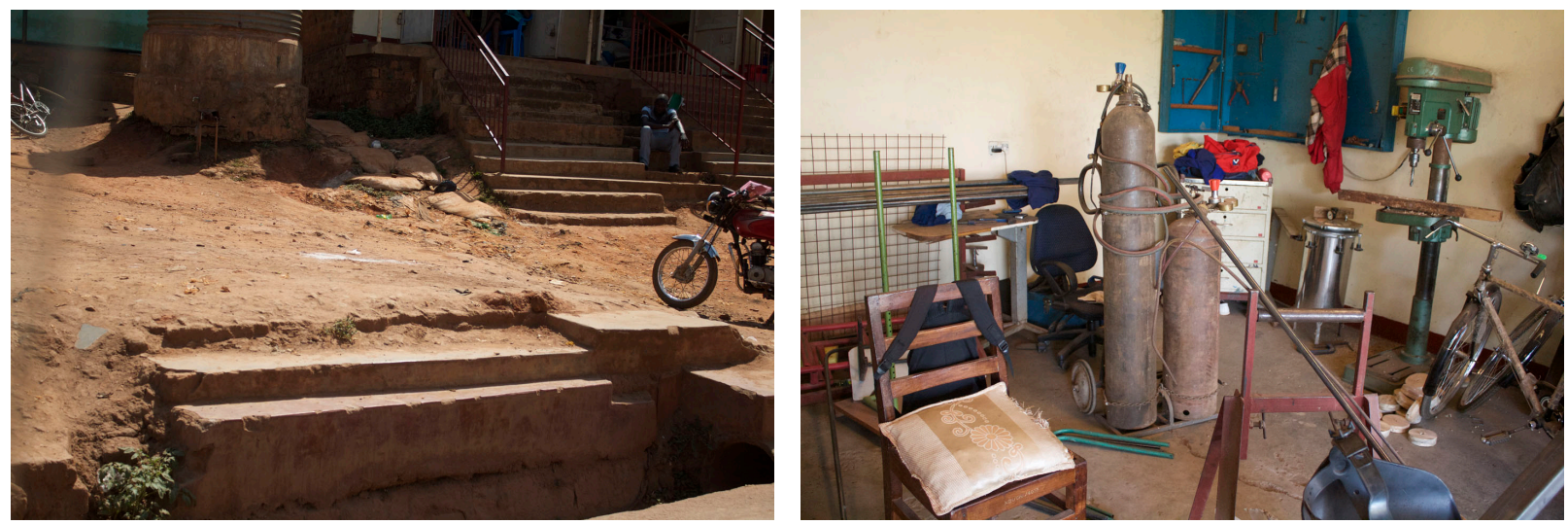

Figure 16 | Infrastructure in Kampala, UG.

Figure 17 | Katalemwa. 


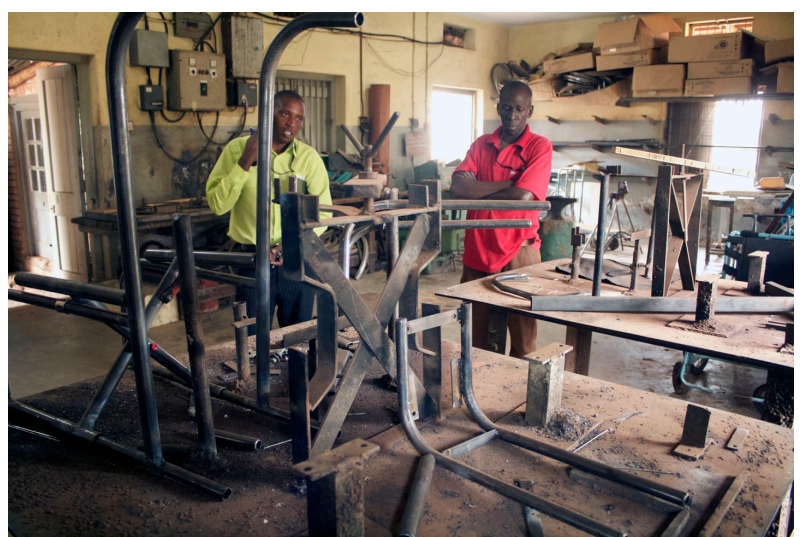

Figure 18 | Mulago.

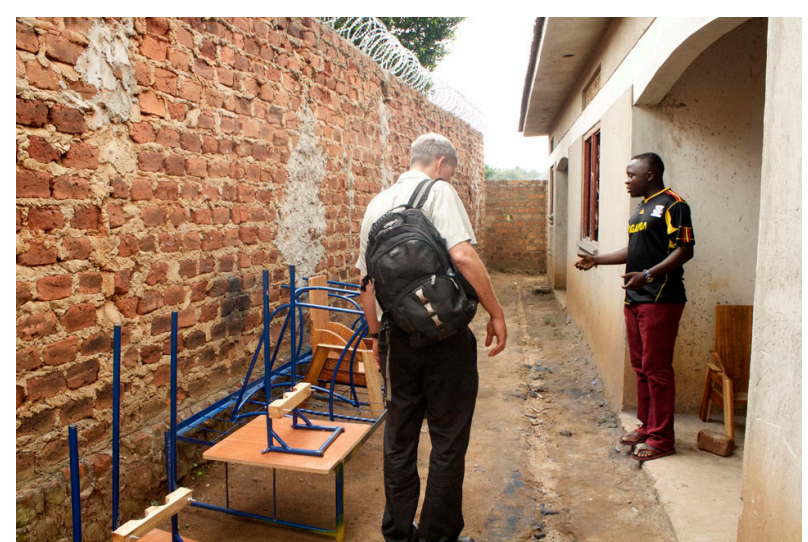

Figure 19 | CDR.

\subsubsection{Wheelchair and/or Tricycle Production}

During the interviews, national producers were asked to describe each type of wheelchair and tricycle they manufacture. They agreed that different types of wheelchairs are suitable to different types of use and different levels of ability, which is why a number of producers offer several types of wheelchairs/tricycles (Maliamungu, 2015; Nsimenta, 2015; Kekihembo, 2015). The following list reports the manufacturers' descriptions of each type of wheelchair and tricycle that they produce:

- Tricycle: suitable for long distance travel over rough surfaces; storage; durable (Fig. 20).

- Huckstep: suitable for rough surfaces; difficult to transfer in and out of; durable (Fig. 21).

- 3-wheeler: suitable for rough surfaces; stable on uneven surfaces; durable (Fig. 22).

- 4-wheeler (rigid): suitable for flat surfaces; unstable on uneven surfaces; durable (Fig. 23).

- 4-wheeler (foldable): suitable for flat surfaces; foldable for transport. 

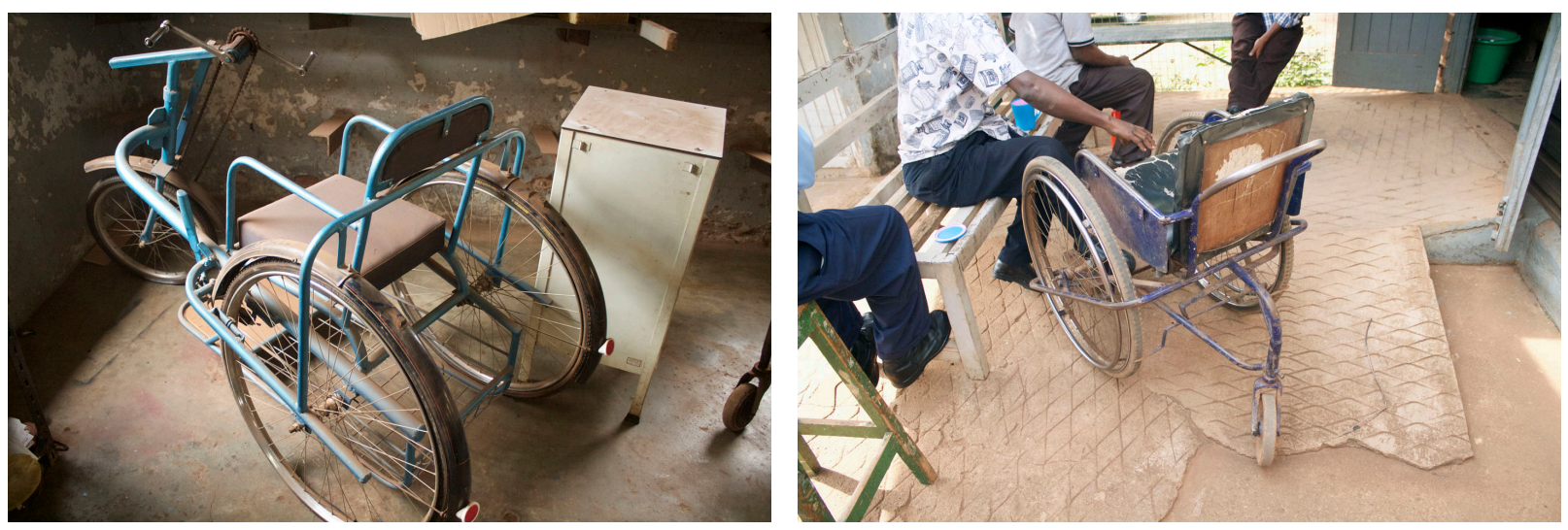

Figure 20 | Tricycle at Mulago.

Figure 21 | Huckstep at Mulago.
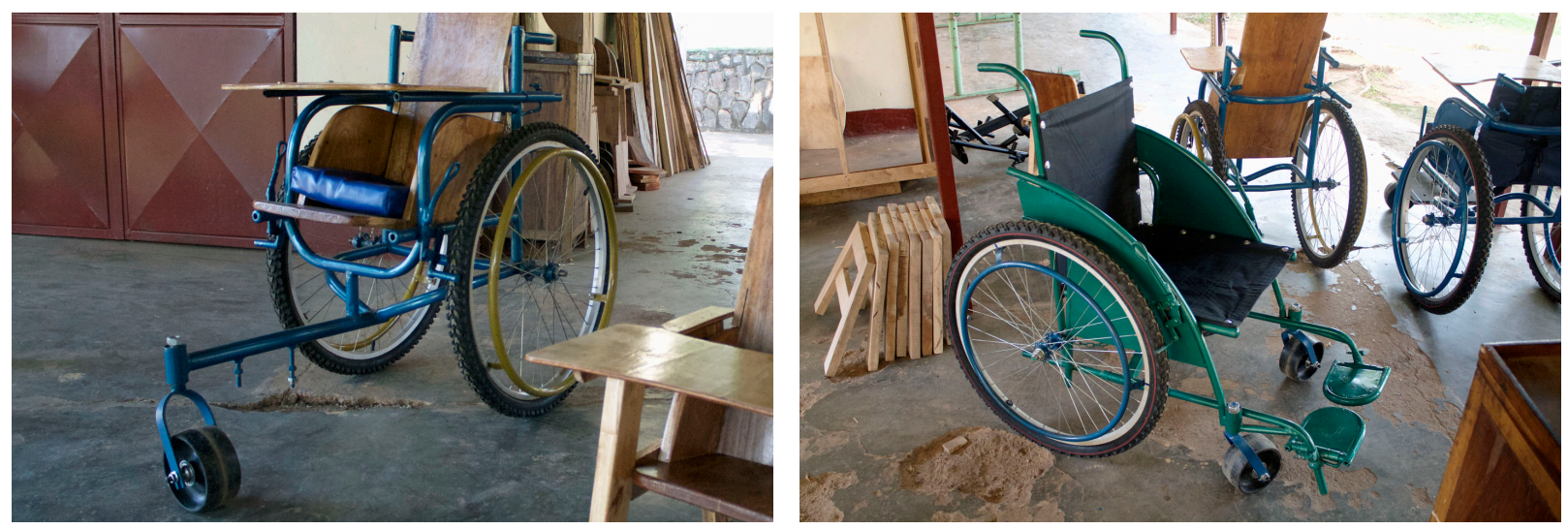

Figure 22 | 3-wheeler at Katalemwa.

Figure 23 | 4-wheeler at Katalemwa.

\subsubsection{Wheelchair and/or Tricycle Prices and Costs}

\subsubsection{Price}

Table 2 reports the types of wheelchairs and tricycles offered by each of the four visited manufacturers in Uganda with prices in Ugandan Shillings (UGX) and US Dollars (USD). 
Table 2

Prices of National Wheelchairs and Tricycles by Type.

\begin{tabular}{|c|c|c|c|c|}
\hline \multirow{2}{*}{ Type } & \multicolumn{4}{|c|}{ Manufacturer } \\
\hline & Katalemwa & Mulago & CDR & Rwenzori \\
\hline Tricycle & $\begin{array}{c}\text { 650,000 UGX } \\
(\$ 188 \text { USD) }\end{array}$ & $\begin{array}{c}\text { 600,000 UGX } \\
(\$ 174 \text { USD })\end{array}$ & $\begin{array}{l}700,000 \text { UGX } \\
(\$ 203 \text { USD) }\end{array}$ & $\begin{array}{l}350,000 \text { UGX } \\
\text { (\$101 USD) }\end{array}$ \\
\hline Huckstep & - & $\begin{array}{c}350,000 \text { UGX } \\
\text { (\$101 USD) }\end{array}$ & $\begin{array}{l}700,000 \cup G X \\
(\$ 203 \text { USD) }\end{array}$ & - \\
\hline 3-wheeler (Rigid) & $\begin{array}{c}\text { 650,000 UGX } \\
\text { (\$188 USD) }\end{array}$ & $\begin{array}{c}500,000 \cup G X \\
(\$ 145 \text { USD })\end{array}$ & $\begin{array}{l}600,000 \cup G X \\
(\$ 174 \text { USD) }\end{array}$ & - \\
\hline 4-wheeler (Rigid) & $\begin{array}{c}\text { 650,000 UGX } \\
(\$ 188 \text { USD) }\end{array}$ & $\begin{array}{l}\text { 400,000 UGX } \\
(\$ 116 \text { USD) }\end{array}$ & - & - \\
\hline 4-wheeler (Foldable) & - & $\begin{array}{c}550,000 \text { UGX } \\
(\$ 159 \text { USD) }\end{array}$ & $\begin{array}{l}700,000 \text { UGX } \\
(\$ 203 \text { USD) }\end{array}$ & - \\
\hline
\end{tabular}

Note. During this research, 1 UGX was equivalent to 0.00029 USD (July 2015).

Table 2 shows that each national producer in Uganda has significantly different prices even though their types of wheelchairs and tricycles offered are identical in design (Observation, 2015). This means that the more expensive manufacturers could probably reduce their prices to be more competitive. After interviewing the local manufacturers and observing their workshops, a few factors seemed to contribute to lower manufacturing costs:

- Labour is the least expensive cost involved with manufacturing a wheelchair or tricycle. For example, parts (e.g. bicycle forks) are often assembled by workers (Figure 24) as it is relatively inexpensive compared to pre-assembled hardware (Observation, 2015). 
- Each worker specializes in only a few operations (Figure 25)(e.g. welding). This approach simplifies the production tasks each worker is responsible for, which has practical benefits in terms of saving time (Observation, 2015)

- The prices of wheelchairs and tricycles in Table 2 tend to be related to the overhead costs of the local manufacturer (Maliamungu, 2015; Nsimenta, 2015; Friday, 2015; Kekihembo, 2015). For example, Rwenzori has a relatively basic workshop with a third of the employees compared to other manufacturers, and their tricycle price reflects this reduction of labour cost.
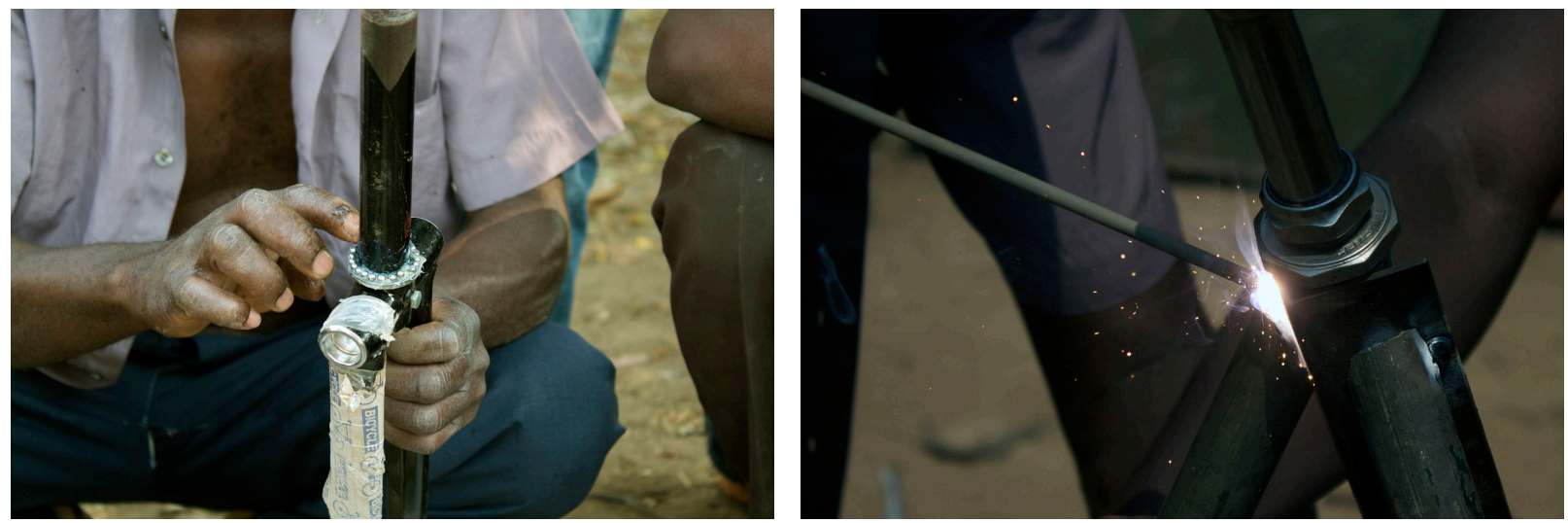

Figure 24 | Hand-assembled forks.

Figure 25 Welding at Rwenzori

\subsubsection{Cost}

Producers explained that the actual cost of a locally manufactured wheelchair or tricycle in terms hardware is difficult to predict because of several different factors, which include: 1) the negotiation abilities of the buyer and seller; 2) the wholesale price that the seller originally paid; 
3) the amount of stock that the seller has at the moment; 4) how familiar the seller is with the buyer; and, 5) how much the seller has sold that day (Friday, 2015; Kekihembo, 2015). During the interviews, local manufacturers estimated that the approximate cost of a wheelchair or tricycle in terms of hardware is approximately $75 \%$ of the total price (Maliamungu, 2015; Friday, 2015). This cost indicates that margins on wheelchairs and tricycles are minimal, if existent at all. See Appendix E for estimated part costs.

\subsubsection{Resources}

All manufacturers reported that they purchase spare parts from local bicycle shops that stock all the parts needed to build either a tricycle or a wheelchair (Maliamungu, 2015; Nsimenta, 2015; Friday, 2015; Kekihembo, 2015). There are exceptions, however; two local manufacturers, Katalemwa and Mulago, reported that they occasionally receive a donated container that carries hardware for wheelchairs and tricycles (Maliamungu, 2015; Nsimenta, 2015). Spare parts purchased from local bicycle shops are usually expensive, particularly in rural settings where multiple margins have been factored into the cost of a given part. Workshops with limited capital and storage reported that buying parts wholesale—and accessing economies of scale-is difficult (Observation, 2015; Maliamungu, 2015; Nsimenta, 2015).

Each manufacturer reported that they employ between four and twelve people who are either contractors or full-time staff (Maliamungu, 2015; Nsimenta, 2015; Friday, 2015; Kekihembo, 2015). Across all manufacturers, each employee had received technical training (Maliamungu, 2015; Nsimenta, 2015; Friday, 2015; Kekihembo, 2015). Kampala-based workshops typically 
employ professional orthopaedic technicians (Maliamungu, 2015; Nsimenta, 2015; Kekihembo, 2015), which means that their employees were trained to specifically build assistive devices. All manufacturers, including the Kasese-based workshop, employ vocationally trained employees (e.g. metalworkers) (Maliamungu, 2015; Nsimenta, 2015; Friday, 2015; Kekihembo, 2015).

Manufacturers have access to a limited amount of tools and equipment, which, to some degree, limits their production capacity. Their equipment and machinery is typically outdated, and while all manufacturers have at least one arc welder, many operations are outsourced because the shop cannot afford to purchase the tools and equipment that they require (Maliamungu, 2015; Nsimenta, 2015; Friday, 2015; Kekihembo, 2015).

\subsubsection{Capacity Building}

Manufacturers reported that the majority of their revenue comes from non-governmental organizations and that government organizations and private sales account for a relatively small fraction of their revenue (Maliamungu, 2015; Nsimenta, 2015; Friday, 2015; Kekihembo, 2015). A number of manufacturers pointed out that funding fluctuates, which varies their monthly revenue, monthly production volumes, and ability to consistently source resources (Maliamungu, 2015; Nsimenta, 2015; Friday, 2015; Kekihembo, 2015). Manufacturers indicated that wheelchair and tricycle production accounts for a relatively small portion of their total revenue (Maliamungu, 2015; Nsimenta, 2015). Rwenzori generates the majority of their revenue from building household metal products (e.g. gates) and the Kampala manufacturers build other assistive devices (e.g. walkers). In all cases, it is not economically sustainable for the 
manufacturers to specialize in producing wheelchairs and tricycles exclusively, despite the significant need for these products.

Katalemwa and Mulago use two production fixtures to weld angles and assemble frames (Figure 26), which were observed to act as guides that allow for some dimensional variation and loose tolerances in the frame (Maliamungu, 2015; Nsimenta, 2015). A number of manufacturers reported that wheelchairs and tricycles will often use parts (e.g. two armrests) that are not the same dimensions as a result of the staff estimating measurements using their builder's intuition (Observation, 2015; Maliamungu, 2015; Friday, 2015). Figure 27 shows a break system from Katalemwa, which is representative of the tighter tolerances produced by manufacturers. It was reported that equipment constraints prevent manufacturers from reducing the size of brakes and other moving parts (Observation, 2015; Maliamungu, 2015). Some manufactures outsource operations if they cannot afford to purchase equipment (Friday, 2015; Kekihembo, 2015). Standardization is relevant to outsourcing because outsourced parts are produced to order. This means that these parts are often expensive and sub-contractors require time to fit the part to the wheelchair or tricycle (Friday, 2015; Kekihembo, 2015). The seats on tricycles built by Rwenzori are produced by a sub-contractor to order, and it was observed that seats require multiple fittings each time a tricycle is made - a process that can take the sub-contractor over an hour (Observation, 2015). 


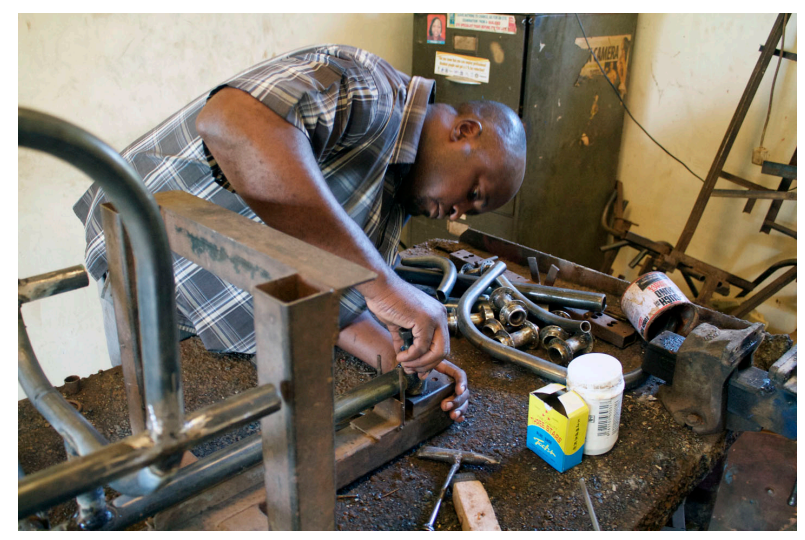

Figure 26 | Production Fixtures.

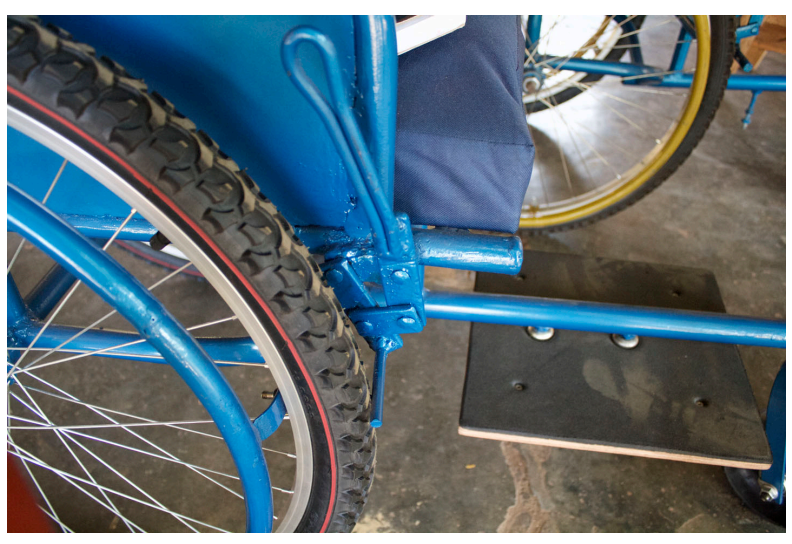

Figure 27 | Break tolerances.

Manufacturers reported relatively low production volumes of 3 to 25 wheelchairs and/or tricycles per month (Maliamungu, 2015; Nsimenta, 2015; Friday, 2015; Kekihembo, 2015). A problem observed during the research was that most manufacturers rely on NGOs to fund wheelchair and/or tricycle production (Maliamungu, 2015; Nsimenta, 2015; Friday, 2015; Kekihembo, 2015). This means that organizations have complete control over the volume of wheelchairs and/ or tricycles produced by the manufacturer each month. Another manufacturing constraint is due to equipment shortages and failures. All manufacturers reported that they need equipment additions, replacements, and/or repairs (Maliamungu, 2015; Nsimenta, 2015; Friday, 2015; Kekihembo, 2015). They often only have one piece of equipment to do a certain operation (e.g. welding), and if that piece of equipment breaks then production stops (Friday, 2015; Kekihembo, 2015). 


\subsection{Imported Large-Scale Production}

\subsubsection{Formal Manufacturing Sector}

It is important to understand why the national fabrication of wheelchairs has transitioned to central manufacturing. Motivation Charitable Trust (Motivation) and Whirlwind Wheelchair International (Whirlwind) — both of which are current ILSPs of wheelchairs-explained that they had previously produced their products in local workshops in Uganda, and other countries, before the turn of the century (Krizack, 2015; Constantinescu, 2015). Both manufacturers reported that the switch to global manufacturing was made to reduce their cost structures and increase their ability to control quality (Krizack, 2015; Constantinescu, 2015). The transition to ILSP was facilitated by international distribution networks, and the byproduct of these networks was access to standardized hardware that had previously varied depending on the setting (King, 2015). Motivation and Whirlwind explained that they are able produce a more standardized wheelchair to a significantly higher degree of quality than nationally fabricated alternatives (Constantinescu, 2015; Krizack, 2015); all of the ILSPs are dedicated to manufacturing appropriate wheelchairs for the context of the majority world. The manufacturers that were interviewed include the two former ILSPs, Motivation and Whirlwind, as well as United Cerebral Palsy Wheels for Humanity (UCP Wheels) and the Free Wheelchair Mission (FWM). 


\subsubsection{Distribution Channels}

When asked about distribution, global manufacturers agreed that the logistics of shipping a container to Uganda are relatively straightforward (Constantinescu, 2015; Krizack, 2015; King, 2015; Schoendorfer, 2015). Depending on the manufacturer, they are capable of shipping between 300 and 550 wheelchairs in a single 40-foot container. Motivation supplied a quote of approximately \$8,295 USD for landing a single 40-foot container in Kampala, Uganda (Jenkins, 2015). This high shipping cost means that it becomes less and less economical for manufacturers to ship anything short of a full container. Depending on the destination, a container can take anywhere from one to six months (Constantinescu, 2015). In Uganda, the researcher met up Motivation at Mulago Hospital, they said that containers take about six months to arrive (Semakula, 2015). Given that global manufacturers want to serve as many organizations as possible, to accommodate small orders, they use the following distribution methods: 1) a full container is delivered to regional distribution centres, which warehouses the wheelchairs before providing them to one or more organizations to distribute to PWDs- these centres are either independent of the manufacturer, franchised by the manufacturer, owned by the manufacturer, or a cooperative between local and global manufacturers (Krizack, 2015; Constantinescu, 2015; King, 2015; Schoendorfer, 2015); or, 2) some wheelchair manufacturers will ship small-quantities of wheelchairs along with other larger orders to reduce the cost of shipping an independent order. This process has lead times of up to 12 months (Constantinescu, 2015) .

Manufacturers disclosed that their supply chain is predominantly one-way and that the former distributors are responsible for reporting product faults and ensuring products are repaired or 
replaced (Constantinescu, 2015; King, 2015). Manufacturers require reports from their distributors to make annual adjustments to their wheelchair designs and to remain aware of the local circumstances (Krizack, 2015; Constantinescu, 2015). A number of manufacturers said that securing reports can be challenging, as many of their local distributors are busy and do not prioritize reports (Krizack, 2015; Constantinescu, 2015).

Bicycles are ubiquitous in Uganda, and, as a result, standardized bicycle hardware is readily available from local bicycle shops (Observation, 2015; Maliamungu, 2015; Nsimenta, 2015; Friday, 2015; Kekihembo, 2015). Bicycle hardware is commonly appropriated for wheelchair and tricycles; in fact, it was observed that many national fabricators use this hardware almost exclusively (Observation, 2015). While global manufacturers use standard bicycle hardware in their wheelchairs, they also use OEM hardware, which can complicate local repairs (Figure 27). A number of manufacturers reported that the bicycle hardware found in local bicycle shops is inferior, and therefore they recommend that organizations purchase all hardware directly from the manufacturers so it can ship with their wheelchair order. However, ILSPs recognize that this approach would only be appropriate for regional distribution centres that have access to secure storage and capital for purchasing replacement hardware (Krizack, 2015).

United Cerebral Palsy has secured $\$ 2,200,000$ in funding from USAID to address shipping costs and lead times with their Project CLASP (Consolidated Logistics for Assistive Technology Supply and Provision) initiative. United Cerebral Palsy claims that Project CLASP will allow organizations to buy small quantities of wheelchairs from multiple global manufacturers-not 
just UCP Wheels. Project CLASP will only be successful if it can be self-sustaining without relying on continual funding and support.

\subsubsection{Wheelchair Prices}

A number of manufacturers sell their wheelchairs to organizations for an approximate price of \$275 USD (landed in Kampala). The exception is the FWM, which uses a cost-driven business model to produce a wheelchair for approximately \$93 USD (landed in Kampala)(Shoendorfer, 2015). In order to make shipping more economical, the FWM ships 550 wheelchairs in 40 -foot containers exclusively. Table 3 reports the wheelchairs offered by each of the four global manufacturers that most closely compare with local alternatives.

Table 3

Estimated prices of imported wheelchairs landed in Kampala

\begin{tabular}{lcccc}
\hline & \multicolumn{4}{c}{ Manufacturer } \\
\cline { 2 - 5 } Price / Wheelchair & Motivation & Whirlwind & UCP Wheels & FWM \\
\hline Wheelchair price & $\$ 245$ USD & \$250 USD & \$250 USD & \$78 USD \\
Freight and other Fees & $\$ 28$ USD & $\$ 28$ USD & \$28 USD & \$15 USD \\
\hline Total landed in Kampala & $\$ 273$ USD & \$278 USD & $\$ 278$ USD & \$93 USD \\
\hline
\end{tabular}

Notes. During this research, 1 UGX was equivalent to 0.00029 USD (July 2015)

Manufacturers reported that limited funding is a major barrier to providing wheelchairs to the majority world (Krizack, 2015; Constantinescu, 2015; King, 2015; Schoendorfer, 2015). Most global manufacturers source funding from a variety organizations, yet the exception is the FWM, who sources their funding from private donations (Schoendorfer, 2015). 


\subsection{Wheelchair Service Delivery}

This section documents results pertaining to wheelchair services in the majority world. Interviews with a local and global producers, organizations, and wheelchair users informs a discussion on issues of wheelchair service delivery.

\subsubsection{Assessment and Prescription}

The services that are provided by local fabricators typically include the assessment of wheelchair users and the prescription of appropriate wheelchairs. Personnel at Mulago have received WHOcompliant training, and the workshop has a designated assessment and prescription room (Observation, 2015; Nsimenta, 2015). Other local fabricators were observed to have lessstructured assessment and prescription services, which were provided by either a physiotherapist or a local disability union (Maliamungu, 2015; Friday, 2015; Kekihembo, 2015)

Globally manufactured wheelchairs and tricycles are provided to wheelchair users in the majority world through two kinds of distributors; regional centres or individual organizations. Motivation and UCP Wheels requires their distributors to have WHO-compliant training, which provisions assessment and prescription services (Constantinescu, 2015; King, 2015). Whirlwind strongly recommends WHO-compliant training to their distributors, and FWM developed their own assessment and prescription program with occupational therapists, which they provide to their distributors (Krizack, 2015; Mugwanya, 2015). 


\subsubsection{Funding and Ordering}

Local and global producers unanimously reported that securing funding is one of the major challenges to successful, widespread wheelchair provision. They reported that organizations typically purchase a number of wheelchairs on behalf of PWDs, and local fabricators reported that government and private sales make up the smallest portion of their revenue for wheelchair production (Krizack, 2015; Constantinescu, 2015; King, 2015; Schoendorfer, 2015).

Global manufacturers reported that the charitable model of wheelchair funding has several negative consequences: 1) wheelchair users typically become dependent on fundraising organizations Observation, 2015; Krizack, 2015; Parekh, 2015); 2) wheelchair users are not accountable for their device (e.g. an organization reported that a wheelchair user sold parts of their wheelchair for income)(Krizack, 2015; Baluku, 2015); and, 3) typically wheelchair users do not have a say in the product that they receive (Krizack, 2015; Constantinescu, 2015; King, 2015). The result is that wheelchair beneficiaries become a passive stakeholder who can only accept what they receive regardless of whether the wheelchair is appropriate for their needs. This is an outcome of wheelchair beneficiaries not being able to purchase assistive devices for themselves. Organizations receive value from manufacturers through measurable outcomes that they can share with their supporters to secure future donations (Constantinescu, 2015; King, 2015) and global manufacturers report that some organizations take a quantity-over-quality approach to wheelchair provision, which often overlooks the need for wheelchair services (Krizack, 2015; Constantinescu, 2015; King, 2015). However, this approach is shifting as organizations become aware of the need for proper provisional services through publications like 
the WHO's Guidelines on the Provision of Manual Wheelchairs in Less-Resourced Settings (Wunderlich, 2015). For example, the Latter Day Saints reported that they changed their model entirely to provide WHO-compliant services to wheelchair users (Constantinescu, 2015; Wunderlich, 2015).

\subsubsection{Product Preparation and Fitting}

All global manufacturers and a number of local fabricators recognize that different types of wheelchairs and tricycles are necessary for different wheelchair users. Products are often modified, either to fit the wheelchair user or to enable the wheelchair user to engage with their community (e.g. income generation [Cox, 2014]). Mulago and Katalemwa reported that they offer globally produced products in addition to their own, and prescribed the appropriate wheelchair depending on the need of the PWD (Nsimenta, 2015; Maliamungu, 2015). Rwenzori offers a tricycle — which is well suited to the Kasese environment—but PWDs revealed that they experience upper chest pain when using the tricycle (Biira, 2015; Baluku, 2015; Bwambale, 2015). To address this, the NGO and tricycle users thought that one of two things should be done by Rwenzori: 1) the gear ratio used on the tricycle should be optimized to accommodate individual ability (Parekh, 2015); or, 2) the Rwenzori should offer a tricycle with an engine (Bahumika, 2015; Kaijuba, 2015; Biira, 2015; Baluku, 2015; Bwambale, 2015). 


\subsubsection{User Training}

According to the WHO-guideline, most PWDs require basic service-delivery and training (WHO, 2008). Mulago uses small booklets, which are illustrated by Motivation and provided with all of their wheelchairs. Personnel also use these booklets as a checklist when training users about using and maintaining their wheelchair. They are only available in English and are not specific to each type of wheelchair because of funding limitations (Nsimenta, 2015). Mulago considers multilingual copies to be an important next step for the booklet (Nsimenta, 2015).

\subsubsection{Follow-Up, Maintenance, and Repairs}

Organizations reported that follow-up is typically complicated by distance. They explained they often do not have the funding to visit wheelchair users in their home and that wheelchair users cannot always come back to where they received their wheelchair (Parekh, 2015; Baluku, 2015).

NSSPs and wheelchair users reported that wheelchairs and tricycles require repairs within three months of receiving the wheelchair, and maintenance is usually required every month thereafter (Nsimenta, 2015; Maliamungu, 2015; Bahumika, 2015; Kaijuba, 2015; Biira, 2015; Baluku, 2015; Bwambale, 2015). The most common type of repair involves replacing pneumatic inner tubes, which are readily available at local bicycle shops (Nsimenta, 2015; Maliamungu, 2015;

Bahumika, 2015; Kaijuba, 2015; Biira, 2015; Baluku, 2015; Bwambale, 2015). Other usual repairs include welding broken wheelchair frames, replacing weathered seats, and realigning brake systems (Nsimenta, 2015; Maliamungu, 2015; Friday, 2015). 


\section{$5 \quad$ Conclusion}

\subsection{Research Questions}

The purpose of this study was to answer the three research questions that were presented in the Methods chapter of this thesis. The research questions that emerged from the literature review are listed below with answers based on the researcher's knowledge, findings, and fieldwork.

Question 1: What are the main barriers that inhibit national small scale production (NSSP) capacity building?

Based on the results of the research, national production is well suited to small-quantity orders in a variety of settings. According to the interviewed and observed manufacturers, the main barriers to NSSP capacity building are standardization, resources, and business training.

NSSP Barrier 1 - Standardization: Nationally produced wheelchairs and tricycles are not standardized. This is because NSSP wheelchairs and tricycles are made entirely by hand. This hand-made approach and the absence of fixtures means that angles and lengths are always different. This is an issue with symmetrical parts on the same product (e.g. uneven armrests). The ad libitum manufacturing causes unreliable product deliveries, which prevents NSSPs from securing larger quantity orders and building their capacity. 
NSSP Barrier 2 - Resources: National producers are highly constrained by absent resources and planning. This was evidenced in Uganda by the number of NSSPs with inadequate production equipment. This can be attributed to two factors: 1) workshops operate day-to-day; and, 2) workshops do not view production equipment as consumables, and therefore they do not secure the capital for replacements. While human resources are easier to acquire in Uganda, it is difficult to maintain staff because of limited funding. Workshop staff is usually trained as apprentices, which means they will absorb time and resources. Once trained, staff will occasionally leave for a better paying job. These absences of reliable resources and planning become a barrier to NSSPs building capacity.

NSSP Barrier 3 - Business Training: National wheelchair producers operate in the informal economy. This was evidenced by NSSPs operating day-to-day and NSSP staff who are sometimes not paid on time. ILSPs that made their wheelchair design in the majority world reported that organizing a sustainable business strategy is difficult. All NSSPs were unable to specify the total cost of their wheelchairs and/or tricycles without the researcher pointing to individual parts and totaling the cost. Unknown costs are partially the result of fluctuating supplier prices; however, if these fluctuations were recorded averages could be calculated. This limited business knowhow is a barrier to NSSPs building capacity.

Question 2: What are the main barriers that inhibit imported large-scale production (ILSP) distribution? 
Based on the results of the research, imported production is well suited to large-quantity and recurring orders in settings with a high population density. According to the interviewed manufacturers, the main barriers to ILSP distribution are micro-logistics and reverse logistics.

Barrier 1 - Micro Logistics: Imported producers have distribution channels that are adequate for large-quantity (i.e. full container) orders; however, long lead times (i.e. up to six-months) can be a deterrent for some customers. Small-quantity orders pose a barrier to ILSP wheelchair distribution, yet optimizing small-quantity supply chains are important for two reasons: 1) there is an opportunity to sell small-quantities to a market of small-scale NGOs; and, 2) smallquantities of spare parts are often needed. ILSPs currently ship spare parts in the container with the original purchase order; however, distributors have a difficult time storing and purchasing this inventory.

Barrier 2 - Reverse Logistics: Imported producers reported that logistics of shipping wheelchairs to people with disabilities (PWDs) in the majority world are relatively straightforward. However, the interviewed ILSPs agreed that wheelchair returns and repairs in the opposite direction are much more complex. In a perfect scenario, reverse logistics would involve: 1) the PWD returning the wheelchair to the distributor; 2) the distributor generating a fault report; 3) the ILSP validating and approving the wheelchair warranty; 4) and the distributor sending the wheelchair for refurbishing or repair (either nationally or internationally); and, 5) the ILSP reducing or eliminating frequently reported faults in future production of their wheelchairs. In the majority world these things usually do not occur so effortlessly. For example, 
PWDs with broken wheelchairs are often stranded in and around their home, which means they are unable to return their broken wheelchair to a distributor.

Question 3: What wheelchair services are offered in the majority world by NSSPs and ILSPs?

During the fieldwork in Uganda, a number of wheelchair services were offered at every NSSP and ILSP distributor. It was clear that everyone who was provisioning wheelchairs was doing their best to provide any services they could. All of the visited NSSPs and ILSP distributors had assessment, funding, product preparation, and fitting services, but only a few of them had prescription, ordering, training, and follow-up services. NSSPs reported that wheelchair services, particularly follow-up services that involve traveling to PWDs, are prohibitively expensive.

\subsection{Limitations}

\subsubsection{Location and Time}

While the research attempted to have representative sample of national producers in rural and urban settings, the distance to different villages made visiting workshops in other areas of Uganda impractical given the fieldwork timeline. In urban settings in Uganda, there are very few traffic regulations, which meant that traffic was often heavy. This meant that visits to workshops in Kampala quickly consumed several hours. The workshop in Kasese was the only representative of workshops in a rural setting, which meant that other workshops in rural settings might be entirely different. When traveling through Kampala, it was observed that there were many 
workshops building products (e.g. door frames) similar to the Kasese workshop. They were not observed to be producing assistive devices, yet it is possible that these workshops could build them. So, while the workshop in Kasese is in a rural setting, it does not confirm that similar workshops are not in urban settings. Different villages and more workshops would need to be visited in order to broaden the scope of this research and provide results that are more representative of Uganda. The limitation on locations and time resulted in a smaller sample size. More representative insights on national production could be gained by conducting research with a greater number of workshops in a greater number of areas.

The research was informed by a number of international producers with limited time. The contacts at these manufacturers were at the management level and they were busy. This meant that coordinating schedules and arranging interviews across different time zones proved to be difficult on a number of occasions. Interviews with different international producers raised different insights and approaches for wheelchair provision in the majority world. There are a number of international producers that were not interviewed because of busy schedules or the timeline of the research. Chances are that these manufacturers have different insights from the one that were interviewed, and more information could be gained by researching them in the future.

\subsubsection{Communication}

The ability to communicate with producers before traveling to Uganda was limited as many of the workshops did not have an easily retrievable telephone number and/or email address. For this 
reason, many telephone numbers were retrieved from participants while in Uganda, which meant that the trip required a certain degree of flexibility. Many of the workshop telephones were frequently unavailable, which made planning and confirming visits difficult. This lack of communication also made it difficult to know which workshops would be best for the research goals. An effort was made to visit a wide variety of workshops with different levels of wheelchairservices. As it turned out, most of the visited workshops in Kampala were attached to rehabilitation facilities. This was because the first workshop visited by the researcher in Kampala was associated with a rehabilitation centre, so the workshops they recommended ended up also having rehabilitation centres. This is one problem with snowball sampling: often the retrieved contact information will skew the sample variety.

International producers are usually traveling to different countries, so arranging interviews became difficult with limited access to telephones and internet. This meant that interviews sometimes needed rescheduling or cancellation, depending on the interview subject's travel arrangements. In the future, it would be best to schedule interviews at least a month or two in advance.

\subsubsection{Sample Size}

The research only represents four national producers in Uganda, four international producers, four international organizations, and six tricycle users in Uganda. All of these participants were either professional or contextual experts in wheelchair provision. The relatively small sample size that can only suggest qualitative insights (i.e. tendencies) when applied to the general issue of 
wheelchair provision in the majority world. In the future, a larger quantitative study should be conducted to substantiate the findings in this research.

\section{$5.3 \quad$ Bias}

This qualitative research project was subject to a number of assumptions. These assumptions came from a lack of understanding of different cultures: the researcher had never travelled outside of North America prior to conducting research in Uganda. Secondary research on wheelchair provision in less-resourced settings was required to research the topic in Uganda. Inevitability, assumptions from secondary research resulted in a degree of bias when collecting information

first-hand. As an example, the third hypothesis in this research project suggested that healthcare services in Uganda were inadequate, which in some cases was not true. This assumption may have had an effect on the way questions about services were asked.

Prior to this research project, Carleton University—specifically in the School of Industrial Design—had done many technical projects in both Uganda and Tanzania. This meant that unpreventable assumptions were made about manufacturers in Uganda that may have influenced interview questions and observation notes. Before this research project, the researcher had been exposed to wheelchair manufacturing in Uganda through undergraduate students, graduate researchers, and their supervisors. While an effort was made to be objective while in Uganda, the nature of qualitative fieldwork is that it will always involve a certain degree of bias. As a result, assumptions may have impacted the data collection methods and, as a byproduct, the findings of the research. 


\subsection{Recommendations for Organizations Using NSSP}

\subsubsection{Provide Wheelchair and/or Tricycle Service Training}

While wheelchair and/or tricycle services are offered in Uganda, they vary considerably from producer to producer and from person to person. If they are not already implementing one, NGOs and governments who purchase from NSSPs should consider providing a budget for wheelchair service training. This training should include creating a checklist that their NSSP can use to assess, prescribe, fit, and train a wheelchair and/or tricycle user. Similarly to Mulago, NGOs and governments should also consider providing the wheelchair/tricycle user with a booklet that explains how the wheelchair/tricycle user can safely use and maintain their wheelchair or tricycle. These documents should be produced in a language that the NSSP and wheelchair/tricycle user can understand.

\subsubsection{Provide Production Equipment}

A number of NSSPs reported that they do not have the capital to purchase basic production equipment. The majority of smaller workshops outsource operations that should be done inhouse, like tube bending, which becomes expensive in terms of the cost of bends, the time to required outsource, and waste produced by tube offcuts. For example, to increase production capacity, Rwenzori explained that they would need to purchase a tube bender for approximately 700,000 UGX, which is equal to about six months rent. Rwenzori explained that a tube bender is too expensive for the workshop to purchase at any given time. NGOs and governments should 
consider providing a budget to their NSSP for production equipment. By providing this funding manufacturing capacity and consistency will increase and ultimately benefit the organization who buys wheelchairs.

If a budget for production equipment is too expensive for NGOs and governments to provide, they should consider providing plans for homemade equipment. For example, it was observed that Rwenzori uses one diameter of tubing and one radius in their tricycle. With a plan for a homemade tube bender, Rwenzori could fabricate a homemade tube bender using readily available materials that are inexpensive (e.g. 20-foot steel tubing can be purchased from a local hardware shop for about 2,000 UGX). The majority of the equipment fabrication could be done by the workshop, with the exception of the die, which could be outsourced to a workshop with a lathe. There are various plans available online for simple, homemade tube benders and other basic production equipment.

\subsubsection{Provide Business Training}

It was observed that NSSPs are part of the informal economy and, as a result, their formal business training is limited. NGOs and governments should consider providing some business training to their NSSP. This training would ultimately help NGOs and governments with capacity building at the national level. Developing a simple business model canvas and cashflow would help business operate more efficiently. For example, with a proper business plan, NSSPs could incorporate the cost of production equipment in products that they produce. This will 
ensure that new production equipment can be purchased when the old production equipment needs replacing.

\subsubsection{Fixture Plans}

Standardization using basic fixtures would improve the consistency of NSSP wheelchairs and tricycles. NGOs and governments should consider providing a budget and plans for fixtures that will allow NSSP capacity building. Katalemwa and Mulago already use fixtures: one fixture holds two pieces of tubing at 90-degrees to facilitate welding, and the other supports wheelchair and tricycle frames while attaching sub-assemblies (e.g. castors). These manufacturers reported that these fixtures are frequently used, but personnel still approximate measurements and estimate angles. This approximation and estimation was observed to cause interference with moving parts on wheelchairs and tricycles. With fixture plans and budget, NSSPs could fabricate a few fixtures to standardize the exact positions of moving parts.

\subsubsection{Optimize Tricycle Gearing}

The tricycles that were observed in Uganda had a single-speed setup that can sometimes be difficult to pedal for tricycle users depending the gearing and diameter of the front wheel. Several questionnaires returned from tricycle users in Kasese indicated that they experience chest and forearm pain when using their tricycle for prolonged periods. Accordingly, NSSPs should consider using a larger $\operatorname{cog}$ - as opposed chainring — on their tricycles. NGOs and governments should have NSSPs test cog sizes to match the strength of the average tricycle user. Modifying 
the cog size is a relatively straightforward operation, as the chainring on the crankset is usually modified by workshops anyways.

\subsubsection{Perform Trials for Variable Speeds}

Uganda, generally, and Kasese, specifically, is quite mountainous, which is another part of the gearing problem. Many tricycle users reported that they sometimes have to be pushed up a hill by a member of their community and stated that they would like a motorized tricycle to be more independent. Trials would be needed to determine the best mechanical design for variable speeds. On one hand, a motor would allow users to travel easily over hills. On the other hand, the structure of the tricycle would need to be modified (increasing production cost) and tricycle users would access to electricity or fuel (increasing personal cost). Alternatively, multiple cogs could be used, but the tolerances of tricycles would need to be improved before this option is viable. Based on stated reasons, it is recommended that NGOs and governments begin with optimizing their current single-speed setup and perform trials before producing tricycles with motors or multiple gears.

\subsubsection{Increase Wheelchair and Tricycle Offerings}

It was observed that some NSSPs only build one type of wheelchair. NGOs and governments should consider having their NSSP build a three-wheeler option for people who do not have the upper body strength to pedal a tricycle. On average, manufacturers in Kampala tend to price their three-wheelers at 10 percent less than the price of their tricycles, making them a more 
economical option. Furthermore, providing a choice to the wheelchair user has practical benefits. For example, even though tricycles can travel long distances-and Kasese is spread out geographically—tricycles are not practical inside and around the home. NGOs and governments should consider offering options to people based on their needs and abilities.

\subsection{Recommendations For ILSPs}

\subsubsection{Use Readily Available Spare Parts}

ILSPs stated that the spare parts they produce and sell can be manufactured and distributed more economically than similar offerings at local bicycle shops in the majority world. They added that their parts are produced to a higher degree of quality. Operating under these assumptions, it was observed that some ILSPs have modified their wheelchairs for a few specialized parts (e.g. brakes). These parts are not readily available at local bicycle shops or easy for NSSPs to reproduce. A problem for organizations who purchase a single container of wheelchairs is that the only way to source specialized parts is to reorder a container from the same ILSP and request that parts are added. The other option is preemptively stocking replacement parts but this would not be viable for organizations without secure storage. This is not to say that ILSPs should not offer spare parts to distributors who have recurring orders, but to point out that distributors and wheelchair users should have an option for accessing spare parts if they only purchase a single container. For these reasons, ILSPs should consider using parts in their wheelchairs that are available at local bicycle shops or parts that can be produced by NSSPs with basic equipment. 


\subsubsection{Engage Communities}

Organizations reported that disabilities are highly stigmatized in the majority world and that many PWDs are marginalized because of their disability. CDR stated that some members of the community are superstitious, believing that disabilities are a curse, and for that reason, PWDs are often left out of their community. ILSPs should consider implementing community engagement programs that educate and foster inclusivity for PWDs; ILSPs can secure funding for these projects and they have the network that can support such programs. For example, MCT has implemented employment programs for parents with children with disabilities and they have installed accessible infrastructure in schools. All ILSPs should consider creating comprehensive programs, which go beyond individual products and services.

\subsection{Future Research and Development}

On more than one occasion, this research project has discussed the significant need for assistive devices, generally, and wheelchairs, specifically, in the majority world. Primary and secondary research indicates that at least 20,000,000 people need a wheelchair, and that most appropriate wheelchairs are between $\$ 200$ and $\$ 300$ USD. This means funding alone to provision that need would reach at least $\$ 4,000,000,000$ USD. This estimate does not factor in the cost of wheelchair services, repairs, and replacements. It was reported that funding is spent on wheelchairs that are not appropriate for the context of the majority world. While this research interviewed a several fundraising organizations, more research is needed in this area to draw definitive conclusions. 
The healthcare service component of wheelchairs provision in the majority world needs to be addressed by more by physiotherapists and occupational therapists. Current healthcare guidelines tend to be complicated and certain factors make guidelines difficult to holistically implement and regulate (e.g. funding limitations). More research is needed to address whether a shorter, consolidated guideline is beneficial-particularly to national wheelchair producers who do not currently standardize their wheelchair services. As it stands, the current guidelines are well-suited to international wheelchair producers.

\subsection{Final Thoughts}

International development efforts have been around for quite some time. While everyone is aware of the significance these efforts, most of us in the so-called "developed world" are quite distanced from the other 90 percent of the world's population. The researcher was in Uganda for a period of 10 days, which felt immersive at the time, but, in reality, was too short to fully understand the complexities of the majority world. The fact is that the majority world has so much to offer, everyone could spend a lifetime of learning.

There is also numerous assumptions made about things that we do not understand. For example, while NSSPs have a limited ability to access resources, during the fieldwork, their resourcefulness appeared to be almost unlimited. The researcher witnessed NSSPs that made wheelchairs out of old tubing off-cuts, used fence posts, and modified bicycle parts. In some cases, these appropriated items were assembled into a wheelchair with a hacksaw blade wrapped in duct tape and a homemade arc welder. NSSPs seem to create objects like magic; with only a mental picture 
of a wheelchair or tricycle in mind, the rest appeared to be intuitive. The study showed that this kind ingenuity and do-it-yourself-ness made observing these workshops the experience of a lifetime.

Everyone involved with the study was very accommodating and more than happy to talk about wheelchair production. In addition to making the research an enjoyable experience, this hospitality made it clear that wheelchair provision is not just a static means to an end, but a dynamic issue that people care about continually working on. The people that have been involved with this research are doing their best to make the world a better place. While an effort was made to keep the research focused on technical issues, there was an empathetic component to the research that could not be excluded or ignored. This was particularly true during the fieldwork in Uganda, where the researcher was surprised by many unexpected events and engaging conversations with many people.

Wheelchair production should not be understood as a a choice between two options, NSSP versus ILSP. The reality is that both methods have a set of factors that need to be understood more clearly before the correct provisional choice can be made by a NGO or government. Hopefully, this study has provided a start for making these important and life-changing decisions. 


\section{Primary References}

Bahumika, J. (2015, July). KADUPEDI Questionnaire. Kasese, Uganda.

Baluku, G. (2015, July). KADUPEDI Questionnaire. Kasese, Uganda.

Baluku, P. (2015, July). Voorneveld, N. Interview. Kasese, Uganda.

Biira, J. (2015, July). KADUPEDI Questionnaire. Kasese, Uganda.

Bwambale, E. (2015, July). KADUPEDI Questionnaire. Kasese, Uganda.

Bwambale, R. (2015, July). Voorneveld, N. Interview. Kasese, Uganda.

Constantinescu, S. (2015, July). Voorneveld, N. Interview. Ottawa, ON, Canada.

Jenkins, K. (2015, July). Voorneveld, N. Shipping Quote Request. Ottawa, ON, Canada.

Kaijuba, J. (2015, July). KADUPEDI Questionnaire. Kasese, Uganda.

King, K. (2015, July). Voorneveld, N. Interview. Ottawa, ON, Canada.

Krizack, M. (2015, July). Voorneveld, N. Interview. Ottawa, ON, Canada.

Maliamungu, V. (2015, July). Voorneveld, N. Interview. Kampala, Uganda.

Mugwanya, F. (2015, July). Voorneveld, N. Interview. Kampala, Uganda.

Nsimenta, D. (2015, July). Voorneveld, N. Interview. Kampala, Uganda.

Parekh, N. (2015, July). Voorneveld, N. Interview. Kampala, Uganda.

Schoendorfer, D. (2015, July). Voorneveld, N. Interview. Ottawa, ON, Canada.

Semakula, F. (2015, July). Voorneveld, N. Interview. Kasese, Uganda.

Wunderlich, E. (2015, July). Voorneveld, N. Interview. Ottawa, ON, Canada. 


\section{Secondary References}

Balaram, S. (2010). Universal design and the majority world. In W. F. Preiser, \& K. H. Smith (Eds.), Universal Design Handbook (p. 3.1 - 3.6). New York, USA: McGraw-Hill.

Beattie, S., Cornick, C. (2006) Wheelchair technology as a profession. Proceedings from: 4th IET Seminar on Appropriate Healthcare Technologies for Developing Countries. UK: IET.

Cox, A. (2014). Income-generating products for people with disabilities in the majority world: Understanding the complexities of participatory design in rural Uganda (Master dissertation). Carleton University, Ottawa, Ontario, Canada.

Free Wheelchair Mission (2015). About Us: Mission and Vision. Retrieved from: www.freewheelchairmission.org/missionandvision on July 2nd, 2015.

GRIT (2015). We Are GRIT. Retrieved from: www.gogrit.org/team/ on July 2nd, 2015.

Hotchkiss, R. (1985). Independence through Mobility: A guide through the manufacture of the ATI-Hotchkiss wheelchair. USA: Appropriate Technology Intl.

Hallgrimsson, B., Liu, C., Hadley, R. (2013) Design for extreme poverty and disability: A social innovation project case study in rural Uganda. Proceedings from: IDSA 2013 Education Symposium. Chicago: IDSA.

Howitt, J., Constantine, D., Hingley, C. A. (2006) Donated wheelchairs in low-income countries: Issues and alternative methods for improving wheelchair provision. Proceedings from: 4th IET Seminar on Appropriate Healthcare Technologies for Developing Countries. UK: IET.

Jaipur Foot (2015). Other Mobility Aids. Retrieved from: http://jaipurfoot.org/what_we_do/ supportive_products/supportive_products.html\#.VeJa1RNVhBc

Jaiswal, A.K. (2007), Strengthen the Bottom of the Pyramid. Retrieved from: http://www.thehindubusinessline.com/todays-paper/tp-opinion/strengthenthe-bottom-of-the-pyramid/article1677780.ece?ref=archive on November 3rd, 2013.

Karnani, A. (2007). The mirage of marketing to the bottom of the pyramid: How the private sector can help alleviate poverty. California Management Review, 49(4), p. 90-111.

King, K. (1977). The African artisan: education and the informal sector in Kenya. Michigan, US: Heinemann. 
Motivation Charitable Trust (2014). About Us: Who We Are. Retrieved from: www.motivation.org.uk/who-are-we/about-us/ on November 8th, 2014.

Mukisa, M.F. (2008). The Status of the Wheelchair in Uganda. Uganda: Uganda National Action Physical Disability.

Øderud, T., Brodtkorb, S., Hotchkiss, R. (2004). Feasibility Study on Production and Provision of Wheelchairs and Tricycles in Uganda. Norway: SINTEF.

Osterwalder, A., Pigneur, Y. (2009). Business Model Generation. Modderman, Denmark.

Sheldon, S. \& Jacobs (2006). Report of a Consensus Conference on Wheelchairs for Developing Countries. Bangalore, India.

SROI Network (2009). A Guide to Social Return on Investment. Retrieved from: www.socialvalueuk.org/what-is-sroi/the-sroi-guide on May 14th, 2015.

UCP Wheels (2015). About Us. Retrieved from: www.ucpwheels.org/about on July 2nd, 2015.

United Nations Industrial Development Organization (2009). Cluster Development for Pro-Poor Growth: the UNIDO Approach. United Nations Industrial Development Organization: Technical Paper Series.

Whirlwind Wheelchair International (2012). Wheelchair Provision and Assembly Centers. Retrieved from: http://www.whirlwindwheelchair.org/wpac on February 13th, 2015.

Winter, A.G. (2006). Assessment of Wheelchair Technology in Tanzania. International Journal for Service Engineering, 2(1), p. 60 - 77.

World Bank (2014). Disability Overview. Retrieved from: www.worldbank.org/en/topic/disability/overview on March 31st, 2014.

World Bank (2005). Urban Informal Sector in Uganda. Key Labour Market Issues Course, UMI GDLC. Retrieved from: info.worldbank.org/etools/docs/library/211247/ Uganda_Urban\%20Sector.pdf on August 15th, 2015.

World Health Organization (2008). Guidelines on the Provision of Manual Wheelchairs in Less Resourced Settings. Geneva, Switzerland.

World Health Organization (2011). World Report on Disability. Geneva, Switzerland. 


\section{Appendix A: Interview Questions}

\section{A.1 Sample Questions for NSSPs}

1 What is your background in terms of wheelchairs/tricycles production?

$2 \quad$ How many employees do you have?

2.1 What are each of their roles at the workshop?

2.2 What is their background? Are they trained?

3 What disabilities do you work with?

3.1 How are your employees trained to deal with disabilities?

$4 \quad$ What production equipment do you use?

4.1 Is there any production equipment that you need to make wheelchairs/tricycles?

$5 \quad$ Do you use fixtures?

5.1 May I photograph them?

6 How many wheelchairs and/or tricycles do you make each month?

6.1 How many to date?

6.2 How many wheelchairs and/or tricycles could you make each month?

6.3 What would need to happen to make more wheelchairs/tricycles per month?

$7 \quad$ What could be improved when making wheelchairs?

8 What slows down production?

9 What repairs are made most often?

10 How do you customize the wheelchair and/or tricycle for the user?

11 Who funds the wheelchair and/or tricycle?

12 What is the price of each type of wheelchair/tricycle that you produce? 
13 Do you know how much each wheelchair and/or tricycle costs in terms of parts?

14 How could you save money when making wheelchairs and/or tricycles?

15 How long does it take (1 employee) to build a wheelchair and/or tricycle?

16 Do you build anything besides wheelchairs and/or tricycles?

17 Can you refer me to another wheelchair and or tricycle maker? 


\section{A.2 Sample Questions for ILSPs}

1 What do you think are the barriers to supplying the need for appropriate wheelchairs?

1.1 What are some of the major challenges with distribution?

1.2 What are some of the major challenges with funding large orders?

1.3 What are some of the major challenges with production and assembly?

1.4 What service-related issues do you encounter?

$2 \quad$ What do you think are the issues with increasing production at the local level?

3 What makes your wheelchairs different from locally-made wheelchairs/tricycles?

3.1 Why don't you produce your design locally?

$4 \quad$ Who pays for your wheelchair?

5 How much does your wheelchair cost?

5.1 Is there bulk pricing available?

6 What is the cost of distribution to Kampala, Uganda?

$7 \quad$ Where are your wheelchairs made?

7.1 Is the production sub-contracted?

7.2 Who manages quality control?

$8 \quad$ Are special spare parts required?

8.1 How are they distributed?

9 What skills, equipment, and tools are required to assemble and repair your wheelchairs? 


\section{A.3 Sample Questions for NGOs}

1 How do you select tricycle and/or wheelchair makers?

2 Why did you choose to make a tricycle or wheelchair?

3 What are the barriers to making more tricycles and/or wheelchairs each month?

$4 \quad$ Would the organization consider purchasing any equipment for their tricycle maker?

5 If you receive more funding to make more tricycles each month, how will you scale?

$6 \quad$ Have you considered purchasing mass-produced options?

\subsection{Would you explain your choice?}

$7 \quad$ What kind of follow-up is done with previous recipients?

8 What standard or guideline do your tricycles and/or wheelchairs follow?

9 How much involvement does the wheelchair recipient have in the tricycle and/or wheelchair?

10 How are tricycle and/or wheelchair recipients selected? 


\section{A.4 Questionnaire for People with Disabilities}

$1 \quad$ What is your name?

$2 \quad$ What is your age?

$3 \quad$ What is your gender?

(Please check one box) $\quad \square$ Female $\square$ Male $\quad \square$ Undisclosed

$4 \quad$ Where do you live?

$5 \quad$ What is your disability?

$6 \quad$ How long have you been disabled?

$7 \quad$ How long have you had the tricycle?

$8 \quad$ Where do you travel on the tricycle?

$\begin{array}{lll}\text { (Please check all that apply) } & \square \text { Work } \quad \square \text { School } \square \text { Neighbourhood } \\ & \square \text { Church } \square \text { Market } \\ & \square \text { Other }\end{array}$

$9 \quad$ How far do you usually travel on the tricycle?
(Please check only one box)
$\begin{array}{ll}\square & 1 \mathrm{Km} \\ \square & 5-10 \mathrm{Km}\end{array}$
$\square 1-3 \mathrm{Km} \quad \square \quad 3-5 \mathrm{Km}$
$\square 10-15 \mathrm{Km} \square 15+\mathrm{Km}$ 
10 How satisfied are you with the tricycle?

(Please check only one box)

$\square$ Not At All Satisfied

$\square$ Somewhat Satisfied

$\square$ Completely Satisfied

$\square$ Slightly Satisfied

$\square$ Very Satisfied

11 What difficulties do you have when using the tricycle?

12 How often do you have the tricycle repaired?

(Please check only one box)

$\square$ Once a month

Once every 3 mths.

$\square$ Once every 6 months

$\square$ Never

$\square$ Once a year

13 What kind of repairs are required more often?

(Please check all that apply)
$\square$ Tricycle Frame
$\square$ Seat
$\square$ Other

$\square$ Wheels

$\square$ Brakes

14 What kind of terrain do you travel on with your tricycle?
(Please check all that apply)
$\square$ Rough stones
$\square$ Hills
$\square$ Other
$\square$ Pavement
$\square$ Sand

15 What suggestions do you have to improve the tricycle?

16 Was your device customized for you? What modifications were made? 
17 Do you have anything you would like to add? 


\section{Appendix B: Result Tables}

\section{B.1 Result Table for NSSPs}

\begin{tabular}{|c|c|c|c|}
\hline \multicolumn{4}{|c|}{ Local Manufacturer } \\
\hline $\begin{array}{l}\text { Katalemwa Cheshire } \\
\text { Home }\end{array}$ & $\begin{array}{l}\text { Rwenzori Metal } \\
\text { Workshop }\end{array}$ & $\begin{array}{l}\text { Mulago Orthopaedic } \\
\text { Workshop }\end{array}$ & $\begin{array}{l}\text { Centre for Disability } \\
\text { \& Rehabilitation }\end{array}$ \\
\hline July 16th, 2015 & July 17th \& 18th, 2015 & July 23rd, 2015 & July 24th, 2015 \\
\hline \multicolumn{4}{|c|}{ Contact Information } \\
\hline Victor Maliamungu & Bwambale Robert & Dennis Nsimenta & $\begin{array}{l}\text { Aneno Sarah } \\
\text { Ocholen }\end{array}$ \\
\hline $\begin{array}{l}\text { Orthopaedic } \\
\text { Technician }\end{array}$ & $\begin{array}{l}\text { KADUPEDI } \\
\text { Organizer }\end{array}$ & $\begin{array}{l}\text { Orthopaedic } \\
\text { Technician }\end{array}$ & $\begin{array}{l}\text { Rehabilitation } \\
\text { Coordinator }\end{array}$ \\
\hline +256772534225 & +256776838292 & +256779658283 & +256793234247 \\
\hline P.O. Box 16548 & P.O. Box 114 & P.O.Box 7051 & P.O. Box 29198 \\
\hline Kampala, Uganda & Kasese, Uganda & Kampala, Uganda & Kampala, Uganda \\
\hline \multicolumn{4}{|l|}{ Staff Information } \\
\hline 12 Staff (full-time) & 4 Staff (contract) & 10 Staff (full-time) & $\begin{array}{l}\text { 4 Staff (full-time) / } 5 \\
\text { staff (contract) }\end{array}$ \\
\hline- & - & - & 2 Administrators \\
\hline- & - & - & $\begin{array}{l}1 \text { Rehabilitation } \\
\text { coordinator }\end{array}$ \\
\hline $\begin{array}{l}4 \text { Prof. trained } \\
\text { orthopaedic tech. }\end{array}$ & - & $\begin{array}{l}10 \text { Prof. trained } \\
\text { orthopaedic tech. }\end{array}$ & \\
\hline $\begin{array}{l}1 \text { Prof. wheelchair } \\
\text { tech. }\end{array}$ & - & - & $\begin{array}{l}1 \text { Prof. trained } \\
\text { wheelchair tech. }\end{array}$ \\
\hline $\begin{array}{l}1 \text { Prof. trained } \\
\text { carpenter }\end{array}$ & - & - & - \\
\hline $\begin{array}{l}1 \text { Prof. trained } \\
\text { shoemaker }\end{array}$ & - & - & - \\
\hline $\begin{array}{l}5 \text { Skilled-trade } \\
\text { workers }\end{array}$ & $\begin{array}{l}4 \text { Skilled-trade } \\
\text { workers (contract) }\end{array}$ & & $\begin{array}{l}5 \text { Skilled-trade } \\
\text { workers (contract) }\end{array}$ \\
\hline Private payroll & Private payroll & Government payroll & Private payroll \\
\hline $\begin{array}{l}\text { Employment } \\
\text { program (Barclay's) }\end{array}$ & - & - & Internship offered \\
\hline
\end{tabular}




\begin{tabular}{|c|c|c|c|}
\hline $\begin{array}{l}\text { Apprenticeship } \\
\text { training model }\end{array}$ & $\begin{array}{l}\text { Apprenticeship } \\
\text { training model }\end{array}$ & $\begin{array}{l}\text { Apprenticeship } \\
\text { training model }\end{array}$ & $\begin{array}{l}\text { Apprenticeship } \\
\text { training model }\end{array}$ \\
\hline \multicolumn{4}{|l|}{ Wheelchairs (UGX) } \\
\hline $\begin{array}{l}\text { 3-Wheeler rigid } \\
(650,000)\end{array}$ & - & $\begin{array}{l}\text { 3-Wheeler Rigid } \\
(500,000)\end{array}$ & $\begin{array}{l}\text { 3-Wheeler Rigid } \\
(600,000)\end{array}$ \\
\hline $\begin{array}{l}\text { 4-Wheeler rigid } \\
(650,000)\end{array}$ & - & $\begin{array}{l}\text { 4-Wheeler Rigid } \\
(400,000)\end{array}$ & - \\
\hline Tricycle $(650,000)$ & Tricycle $(350,000)$ & Tricycle $(600,000)$ & Tricycle $(700,000)$ \\
\hline- & - & Huckstep $(350,000)$ & Huckstep $(700,000)$ \\
\hline- & - & $\begin{array}{l}\text { 4-Wheeler folding } \\
(550,000)\end{array}$ & $\begin{array}{l}\text { 4-Wheeler folding } \\
(700,000)\end{array}$ \\
\hline \multicolumn{4}{|c|}{ Current Production Equipment } \\
\hline $\begin{array}{l}2 \text { Arc welders (40- } \\
\text { yrs. old) }\end{array}$ & $\begin{array}{l}2 \text { Homemade arc } \\
\text { welders }\end{array}$ & $\begin{array}{l}1 \text { Arc welders (40- } \\
\text { yrs. old) }\end{array}$ & 1 Arc welder \\
\hline 1 Oxyacetylene torch & $\begin{array}{l}\text { No oxyacetylene } \\
\text { torch }\end{array}$ & 1 Oxyacetylene torch & $\begin{array}{l}\text { No oxyacetylene } \\
\text { torch }\end{array}$ \\
\hline 1 Machine lathe & No machine lathe & 1 Machine lathe & No machine lathe \\
\hline $\begin{array}{l}2 \text { Drill presses (40- } \\
\text { yrs. old) }\end{array}$ & No drill press & $\begin{array}{l}1 \text { Drill presses (40- } \\
\text { yrs. old) }\end{array}$ & 1 Drill press (broken) \\
\hline $\begin{array}{l}1 \text { Bench grinder (40- } \\
\text { yrs. old) }\end{array}$ & No bench grinder & 1 Bench grinder & No bench grinder \\
\hline 1 Angle grinder & 1 Angle grinder & 1 Angle grinder & 1 Angle grinder \\
\hline 3 Tube benders & $\begin{array}{l}\text { No tube bender } \\
\text { (outsourced) }\end{array}$ & 3 Tube benders & $\begin{array}{l}1 \text { Homemade tube } \\
\text { bender }\end{array}$ \\
\hline $\begin{array}{l}3 \text { Workbenches with } \\
\text { bench vices }\end{array}$ & 1 Bench vice & $\begin{array}{l}5 \text { Workbenches with } \\
\text { bench vices }\end{array}$ & 1 Bench vice \\
\hline \multicolumn{4}{|c|}{ Needed Production Equipment } \\
\hline $\begin{array}{l}\text { Additional arc } \\
\text { welders }\end{array}$ & - & $\begin{array}{l}\text { Additional arc } \\
\text { welders }\end{array}$ & - \\
\hline- & $\begin{array}{l}\text { Tube bender } \\
\text { (currently } \\
\text { outsourced) }\end{array}$ & - & $\begin{array}{l}\text { Tube bender } \\
\text { (currently } \\
\text { outsourced) }\end{array}$ \\
\hline- & Tube cutter & - & - \\
\hline- & - & $\begin{array}{l}\text { Compressor \& Spray } \\
\text { Gun (currently } \\
\text { brushed) }\end{array}$ & $\begin{array}{l}\text { Compressor \& Spray } \\
\text { Gun (currently } \\
\text { brushed) }\end{array}$ \\
\hline
\end{tabular}




\begin{tabular}{|c|c|c|c|}
\hline- & - & Sewing machines & - \\
\hline $\begin{array}{l}\text { To increase quality } \\
\text { and volume }\end{array}$ & - & $\begin{array}{l}\text { To increase quality } \\
\text { and volume }\end{array}$ & - \\
\hline $\begin{array}{l}\text { General updates to } \\
\text { older machines }\end{array}$ & $\begin{array}{l}\text { General updates to } \\
\text { older machines }\end{array}$ & $\begin{array}{l}\text { General updates to } \\
\text { older machines }\end{array}$ & $\begin{array}{l}\text { General updates to } \\
\text { older machines }\end{array}$ \\
\hline \multicolumn{4}{|c|}{ Production Volume \& Description } \\
\hline $\begin{array}{l}\text { Avg. Volume: 10-20/ } \\
\text { month }\end{array}$ & $\begin{array}{l}\text { Avg. Volume: 3-5/ } \\
\text { month }\end{array}$ & $\begin{array}{l}\text { Avg. Volume: 15-25/ } \\
\text { month }\end{array}$ & $\begin{array}{l}\text { Avg. Volume: 3-20/ } \\
\text { month }\end{array}$ \\
\hline $\begin{array}{l}\text { Max. Volume: 100/ } \\
\text { month }\end{array}$ & $\begin{array}{l}\text { Max. Volume: 20/ } \\
\text { month }\end{array}$ & $\begin{array}{l}\text { Max. Volume: 50/ } \\
\text { month }\end{array}$ & $\begin{array}{l}\text { Max. Volume: 20/ } \\
\text { month }\end{array}$ \\
\hline $\begin{array}{l}\text { Welding \& assembly } \\
\text { fixtures }\end{array}$ & $\begin{array}{l}\text { No welding or } \\
\text { assembly fixtures }\end{array}$ & $\begin{array}{l}\text { Welding \& assembly } \\
\text { fixtures }\end{array}$ & $\begin{array}{l}90 \circ \text { Corner welding } \\
\text { fixtures only }\end{array}$ \\
\hline Not standardized & Not standardized & WHO-compliant* & Not standardized \\
\hline \multicolumn{4}{|c|}{ Barriers to Increase Production Volume } \\
\hline Lack of supplies & $\begin{array}{l}\text { Lack of supplies } \\
\text { (Rwenzori sources } \\
\text { parts from local } \\
\text { suppliers as they're } \\
\text { working on the } \\
\text { wheelchair) }\end{array}$ & Lack of supplies & Lack of supplies \\
\hline $\begin{array}{l}\text { Lack of functional } \\
\text { equipment } \\
\text { (Katalemwa's } \\
\text { machinery is German } \\
\text { which means they } \\
\text { need to source } \\
\text { special parts and } \\
\text { labour for repairs) }\end{array}$ & $\begin{array}{l}\text { Lack of functional } \\
\text { equipment (An angle } \\
\text { grinder broke during } \\
\text { the build and it took } \\
\text { almost three hours to } \\
\text { repair and there was } \\
\text { no backup) }\end{array}$ & $\begin{array}{l}\text { Lack of functional } \\
\text { equipment (As a } \\
\text { result of having } \\
\text { many staff and one } \\
\text { welder, Mulago has a } \\
\text { long queue for } \\
\text { welding) }\end{array}$ & $\begin{array}{l}\text { Lack of functional } \\
\text { equipment }\end{array}$ \\
\hline $\begin{array}{l}\text { Lack of staff } \\
\text { motivation } \\
\text { (Katalemwa } \\
\text { previously provided } \\
\text { incentives to staff } \\
\text { based on their } \\
\text { output). }\end{array}$ & - & - & - \\
\hline
\end{tabular}

\section{Common Repairs to Wheelchairs}

\begin{tabular}{llll}
\hline Tires & Tires & - & - \\
\hline Inner tubes & Inner tubes & Inner tubes & Inner tubes \\
\hline Frame (corrosion) & Frame (welds) & - & - \\
\hline Seats (UV damage) & Seats (UV damage) & Seats (UV damage) & Seats (UV damage) \\
\hline
\end{tabular}




\begin{tabular}{llll}
\hline- & Brakes & - & - \\
\hline- & - & $\begin{array}{l}3 \text { Months until first } \\
\text { repair }\end{array}$ & - \\
\hline
\end{tabular}

"Poor communities

often choose

necessities over

wheelchair repairs

and sometimes

wheelchairs are

abandoned"

\section{Suppliers}

\begin{tabular}{llll}
\hline $\begin{array}{l}\text { Large inventory of } \\
\text { supplies }\end{array}$ & $\begin{array}{l}\text { No inventory of } \\
\text { supplies (due to a } \\
\text { lack of capital and a } \\
\text { lack of secure } \\
\text { storage space) }\end{array}$ & $\begin{array}{l}\text { Large inventory of } \\
\text { supplies }\end{array}$ & $\begin{array}{l}\text { Small inventory of } \\
\text { supplies }\end{array}$ \\
\hline $\begin{array}{l}\text { Purchased from local } \\
\text { hardware stores at } \\
\text { wholesale prices. }\end{array}$ & $\begin{array}{l}\text { Purchased from local } \\
\text { hardware stores at } \\
\text { negotiated prices. }\end{array}$ & $\begin{array}{l}\text { Purchased from local } \\
\text { hardware stores at } \\
\text { wholesale prices. }\end{array}$ & $\begin{array}{l}\text { Purchased from local } \\
\text { hardware stores at } \\
\text { wholesale prices. }\end{array}$ \\
\hline & $\begin{array}{l}\text { Supplies are } \\
\text { purchased during the } \\
\text { tricycle build (the } \\
\text { tricycle is not } \\
\text { standardized, } \\
\text { therefore, } \\
\text { outsourced parts } \\
\text { need to be fitted to } \\
\text { each individual } \\
\text { tricycle) resulting in } \\
\text { delays. }\end{array}$ & \\
\hline
\end{tabular}

Wheelchair Services

\begin{tabular}{llll}
\hline- & - & WHO-compliant* & $\begin{array}{l}\text { Physiotherapist } \\
\text { services }\end{array}$ \\
\hline $\begin{array}{l}\text { Individual } \\
\text { assessment }\end{array}$ & $\begin{array}{l}\text { No assessment or } \\
\text { prescription }\end{array}$ & $\begin{array}{l}\text { Individual } \\
\text { assessment }\end{array}$ & $\begin{array}{l}\text { Community } \\
\text { assessment }\end{array}$ \\
\hline $\begin{array}{l}\text { Fitted to the } \\
\text { beneficiary }\end{array}$ & $\begin{array}{l}\text { Fitted to the } \\
\text { beneficiary }\end{array}$ & $\begin{array}{l}\text { Fitted to the } \\
\text { beneficiary }\end{array}$ & $\begin{array}{l}\text { Fitted to the } \\
\text { beneficiary }\end{array}$ \\
\hline $\begin{array}{l}\text { Maintenance \& use } \\
\text { training }\end{array}$ & No training & $\begin{array}{l}\text { Maintenance \& use } \\
\text { training }\end{array}$ & $\begin{array}{l}\text { Maintenance \& use } \\
\text { training }\end{array}$ \\
\hline $\begin{array}{l}\text { Payment } \\
\text { Payming }\end{array}$ & Organizations (e.g. \\
$\begin{array}{l}\text { Christian Blinded } \\
\text { Mission) }\end{array}$ & $\begin{array}{l}\text { Organizations (e.g. } \\
\text { CanUgan) }\end{array}$ & $\begin{array}{l}\text { Organizations (e.g. } \\
\text { Latter Day Saints) }\end{array}$ & $\begin{array}{l}\text { Organizations (e.g. } \\
\text { Christian Blinded } \\
\text { Mission) }\end{array}$ \\
\hline
\end{tabular}




\begin{tabular}{llll}
\hline $\begin{array}{l}\text { Banks (e.g. Barclay's } \\
\begin{array}{l}\text { Employment } \\
\text { Program) }\end{array}\end{array}$ & - & $\begin{array}{l}\text { Government (funds } \\
\text { staff payroll and 1.6 } \\
\text { wheelchairs per } \\
\text { month) }\end{array}$ & $\begin{array}{l}\text { Private Buyers (e.g. } \\
\text { families and friends) }\end{array}$ \\
\hline Profits & - & Profits \\
\hline Labour Inputs & & & \\
\hline $\begin{array}{l}36-40 \text { Hrs. / } \\
\text { wheelchair or tricycle }\end{array}$ & $40 \mathrm{Hrs}$ / tricycle & $\begin{array}{l}32 \mathrm{Hrs} / \text { wheelchair } \\
\text { or tricycle }\end{array}$ & $\begin{array}{l}36 \mathrm{Hrs} \text { / wheelchair } \\
\text { or tricycle }\end{array}$ \\
\hline
\end{tabular}

*Reference: Guidelines on the Provision of Manual Wheelchairs in Less-Resourced Settings (World Health Organization, 2008) 


\section{B.2 Result Table for ILSPs}

\begin{tabular}{|c|c|c|c|}
\hline \multicolumn{4}{|c|}{ Global Manufacturer } \\
\hline $\begin{array}{l}\text { Motivation Charitable } \\
\text { Trust }\end{array}$ & $\begin{array}{l}\text { UCP Wheels for } \\
\text { Humanity }\end{array}$ & $\begin{array}{l}\text { Free Wheelchair } \\
\text { Mission }\end{array}$ & $\begin{array}{l}\text { Whirlwind } \\
\text { Wheelchair }\end{array}$ \\
\hline July 2nd, 2015 & July 7th, 2015 & July 11th, 2015 & July 13th, 2015 \\
\hline \multicolumn{4}{|c|}{ Contact Information } \\
\hline $\begin{array}{l}\text { Stefan } \\
\text { Constantinescu }\end{array}$ & Keoke King & $\begin{array}{l}\text { Dr. Don } \\
\text { Schoendorfer }\end{array}$ & Marc Krizack \\
\hline $\begin{array}{l}\text { Technical Manager } \\
\text { (20 years) }\end{array}$ & $\begin{array}{l}\text { Product Division } \\
\text { Manager ( } 3 \text { years) }\end{array}$ & Founder (14 years) & $\begin{array}{l}\text { Executive Director } \\
\text { (12 years) }\end{array}$ \\
\hline $\begin{array}{l}\text { Contact researcher } \\
\text { for phone }\end{array}$ & $\begin{array}{l}\text { Contact researcher } \\
\text { for phone }\end{array}$ & $\begin{array}{l}\text { Contact researcher } \\
\text { for phone }\end{array}$ & $\begin{array}{l}\text { Contact researcher } \\
\text { for phone }\end{array}$ \\
\hline Ontario, Canada & California, USA & California, USA & California, USA \\
\hline \multicolumn{4}{|c|}{ Wheelchair \& Shipping Prices (USD) } \\
\hline WHO-compliant* & WHO-compliant* & $\begin{array}{l}\text { Standardized in } \\
\text { partnership with a } \\
\text { local university. }\end{array}$ & WHO-compliant* \\
\hline Rough Terrain $\$ 245$ & $\begin{array}{l}\text { Acitve Wheelchair } \\
\$ 250\end{array}$ & Gen. 1 \& Gen. $2 \$ 78$ & RoughRider $\$ 250$ \\
\hline $\begin{array}{l}\text { Approximate cost of } \\
\text { landing in Kampala, } \\
\text { Uganda } \$ 33 / \$ 43 \\
\text { (Based on a } \$ 10,000 \\
\text { quote to ship a } 40 \\
\text { container filled with } \\
\text { approximately } 300 \\
\text { wheelchairs) }\end{array}$ & $\begin{array}{l}\text { Approximate cost of } \\
\text { landing in Kampala, } \\
\text { Uganda } \$ 33 / \$ 43 \\
\text { (Based on a } \$ 10,000 \\
\text { quote to ship a } 40 \\
\text { container filled with } \\
\text { approximately } 300 \\
\text { wheelchairs) }\end{array}$ & $\begin{array}{l}\text { Approximate cost of } \\
\text { landing in Kampala, } \\
\text { Uganda } \$ 19 / \$ 25 \\
\text { (Based on a } \$ 10,000 \\
\text { quote to ship a } 40, \\
\text { container filled with } \\
550 \text { wheelchairs) }\end{array}$ & $\begin{array}{l}\text { Approximate cost of } \\
\text { landing in Kampala, } \\
\text { Uganda } \$ 33 / \$ 43 \\
\text { (Based on a } \$ 10,000 \\
\text { quote to ship a } 40 \text { ' } \\
\text { container filled with } \\
\text { approximately } 300 \\
\text { wheelchairs) }\end{array}$ \\
\hline $\begin{array}{l}\text { Also produces } 15 \\
\text { other wheelchairs } \\
\text { that are WHO- } \\
\text { compliant* }\end{array}$ & $\begin{array}{l}\text { Also produces an } \\
\text { intermediate } \\
\text { wheelchair that is } \\
\text { WHO-compliant* }\end{array}$ & $\begin{array}{l}\text { Also produces a } \\
\text { folding version of the } \\
\text { Gen. } 2 \text { wheelchair. }\end{array}$ & - \\
\hline
\end{tabular}

\section{Manufacturing Information}

\begin{tabular}{llll}
\hline China & China and Indonesia & China & China and Vietnam \\
\hline
\end{tabular}




\begin{tabular}{|c|c|c|c|}
\hline Subcontracted & Subcontracted & Subcontracted & Subcontracted \\
\hline $\begin{array}{l}\text { Previously in India } \\
\text { (returned to China } \\
\text { for economical } \\
\text { reasons) }\end{array}$ & - & - & - \\
\hline $\begin{array}{l}\text { Volume: } \\
\text { Approximately } \\
\text { 50,000/year }\end{array}$ & - & $\begin{array}{l}\text { Volume: 60,000- } \\
\text { 90,000/year }\end{array}$ & - \\
\hline MOQ: 50 wheelchairs & MOQ: 10 wheelchairs & $\begin{array}{l}\text { MOQ: } 550 \\
\text { wheelchairs }\end{array}$ & MOQ: 1 wheelchair \\
\hline $\begin{array}{l}\text { Assembled locally by } \\
\text { distributor }\end{array}$ & $\begin{array}{l}\text { Assembled locally by } \\
\text { distributor }\end{array}$ & $\begin{array}{l}\text { Assembled locally by } \\
\text { distributor }\end{array}$ & $\begin{array}{l}\text { Assembled locally by } \\
\text { distributor }\end{array}$ \\
\hline $\begin{array}{l}\text { QC managed by } \\
\text { Motivation }\end{array}$ & $\begin{array}{l}\text { QC managed by UCP } \\
\text { Wheels }\end{array}$ & $\begin{array}{l}\text { QC managed by the } \\
\text { Free Wheelchair } \\
\text { Mission }\end{array}$ & $\begin{array}{l}\text { QC managed by } \\
\text { Whirlwind }\end{array}$ \\
\hline \multicolumn{4}{|l|}{ Repair Information } \\
\hline $\begin{array}{l}\text { Repair kit is included } \\
\text { in the box }\end{array}$ & $\begin{array}{l}\text { Repair kit is included } \\
\text { in the box }\end{array}$ & $\begin{array}{l}\text { Repair kit is included } \\
\text { in the box }\end{array}$ & $\begin{array}{l}\text { Repair kit is included } \\
\text { in the box }\end{array}$ \\
\hline $\begin{array}{l}\text { Repairs require only } \\
\text { basic skills }\end{array}$ & $\begin{array}{l}\text { Repairs require only } \\
\text { basic skills }\end{array}$ & $\begin{array}{l}\text { Repairs require only } \\
\text { basic skills }\end{array}$ & $\begin{array}{l}\text { Repairs require only } \\
\text { basic skills }\end{array}$ \\
\hline $\begin{array}{l}\text { Spare parts are } \\
\text { added to the initial } \\
\text { container; selected } \\
\text { based on common } \\
\text { repairs }\end{array}$ & $\begin{array}{l}\text { Spare parts are } \\
\text { added to the initial } \\
\text { container; selected } \\
\text { based on common } \\
\text { repairs }\end{array}$ & $\begin{array}{l}\text { Spare parts are } \\
\text { added to the initial } \\
\text { container; selected } \\
\text { based on common } \\
\text { repairs }\end{array}$ & $\begin{array}{l}\text { Spare parts are } \\
\text { added to the initial } \\
\text { container; selected } \\
\text { based on common } \\
\text { repairs }\end{array}$ \\
\hline $\begin{array}{l}\text { Responsibility of the } \\
\text { distributor to } \\
\text { manage their } \\
\text { inventory of spare } \\
\text { parts and request } \\
\text { additional spare } \\
\text { parts in future } \\
\text { shipments. }\end{array}$ & $\begin{array}{l}\text { Responsibility of the } \\
\text { distributor to } \\
\text { manage their } \\
\text { inventory of spare } \\
\text { parts and request } \\
\text { additional spare } \\
\text { parts in future } \\
\text { shipments. }\end{array}$ & $\begin{array}{l}\text { Responsibility of the } \\
\text { distributor to } \\
\text { manage their } \\
\text { inventory of spare } \\
\text { parts and request } \\
\text { additional spare } \\
\text { parts in future } \\
\text { shipments. }\end{array}$ & $\begin{array}{l}\text { Responsibility of the } \\
\text { distributor to } \\
\text { manage their } \\
\text { inventory of spare } \\
\text { parts and request } \\
\text { additional spare } \\
\text { parts in future } \\
\text { shipments. }\end{array}$ \\
\hline
\end{tabular}

Iterations to the wheelchair are made using fault reports that the distributor is responsible for.

*Reference: Guidelines on the Provision of Manual Wheelchairs in Less-Resourced Settings (World Health Organization, 2008 


\section{B.3 Result Table for People with Disabilities}

\begin{tabular}{|c|c|c|c|c|}
\hline \multicolumn{5}{|c|}{ Beneficiary Information } \\
\hline $\begin{array}{l}\text { Bahumika } \\
\text { Josseline }\end{array}$ & Kaijuba John & Biira Margaret & Baluku Geofrey & Bwanbale Edgar \\
\hline July 12th, 2015 & July 15th, 2015 & July 11th, 2015 & July 11th, 2015 & July 11th, 2015 \\
\hline \multicolumn{5}{|l|}{ Age } \\
\hline 30 & 47 & 32 & 42 & 20 \\
\hline \multicolumn{5}{|l|}{ Gender } \\
\hline Female & Male & Female & Male & Male \\
\hline \multicolumn{5}{|c|}{ Where do you live? } \\
\hline Kabuyiri & Kabuyiri & Maliba Village & Nyakasamga & Ibanda Village \\
\hline \multicolumn{5}{|c|}{ What is your disability? } \\
\hline Physical & Physical & Physical & Physical & Physical \\
\hline \multicolumn{5}{|c|}{ How many years have you been disabled? } \\
\hline 23 Years & 45 Years & 29 Years & 34 Years & 4 Years \\
\hline \multicolumn{5}{|c|}{ How many years have you had your tricycle? } \\
\hline 4 Years & 4 Years & 22 [Months?] & 19 Years [?] & 1 Year \\
\hline \multicolumn{5}{|c|}{ Where do you travel on your tricycle? } \\
\hline $\begin{array}{l}\text { Church, market, } \\
\text { and } \\
\text { neighbourhood }\end{array}$ & $\begin{array}{l}\text { Church, market, } \\
\text { and } \\
\text { neighbourhood. } \\
\text { Carrying food } \\
\text { from the garden. }\end{array}$ & $\begin{array}{l}\text { Work, church, } \\
\text { market, and } \\
\text { neighbourhood }\end{array}$ & $\begin{array}{l}\text { Work, } \\
\text { neighbourhood, } \\
\text { church, market, } \\
\text { and garden. }\end{array}$ & $\begin{array}{l}\text { Work, } \\
\text { neighbourhood, } \\
\text { church, and } \\
\text { market. }\end{array}$ \\
\hline \multicolumn{5}{|c|}{ How far do you usually travel on your tricycle? } \\
\hline $3-5 \mathrm{Km}$ & $1-3 \mathrm{Km}$ & $1-3 \mathrm{Km}$ & $5-10 \mathrm{Km}$ & $1-3 \mathrm{Km}$ \\
\hline
\end{tabular}

\begin{tabular}{|c|c|c|c|c|}
\hline \multicolumn{5}{|c|}{ How satisfied are you with the tricycle? } \\
\hline Very satisfied & $\begin{array}{l}\text { Completely } \\
\text { satisfied }\end{array}$ & Very satisfied & $\begin{array}{l}\text { Completely } \\
\text { Satisfied }\end{array}$ & $\begin{array}{l}\text { Completely } \\
\text { Satisfied }\end{array}$ \\
\hline
\end{tabular}




\section{What difficulties do you experience when using the tricycle?}

\begin{tabular}{|c|c|c|c|c|}
\hline $\begin{array}{l}\text { Get difficulties } \\
\text { moving in a hilly } \\
\text { places }\end{array}$ & $\begin{array}{l}\text { Get tired while } \\
\text { climbing hills } \\
\text { and slopes }\end{array}$ & $\begin{array}{l}\text { A lot of pain } \\
\text { during travelling, } \\
\text { cough when } \\
\text { using it for long, } \\
\text { headache. Then } \\
\text { it makes me } \\
\text { tired. }\end{array}$ & $\begin{array}{l}\text { Chest pain, joint } \\
\text { pain, a lot of } \\
\text { sunshine and } \\
\text { rains during the } \\
\text { rain seasons. }\end{array}$ & $\begin{array}{l}\text { Sometimes get } \\
\text { tired, falling } \\
\text { down in the } \\
\text { rough road, } \\
\text { back ache, pain } \\
\text { when seated for } \\
\text { a long time on } \\
\text { the seat. }\end{array}$ \\
\hline
\end{tabular}

\section{How often do you have the tricycle repaired?}

\begin{tabular}{|c|c|c|c|c|}
\hline Once a year & Once a month & Once a month & $\begin{array}{l}\text { Once every } 3 \\
\text { months }\end{array}$ & Once a month \\
\hline \multicolumn{5}{|c|}{ What kind of repairs are made most often? } \\
\hline $\begin{array}{l}\text { Wheels and } \\
\text { brakes }\end{array}$ & Wheels & $\begin{array}{l}\text { Wheels, brakes, } \\
\text { and tires }\end{array}$ & $\begin{array}{l}\text { Wheels, brakes, } \\
\text { and seat }\end{array}$ & Tires and brakes \\
\hline
\end{tabular}

What kind of terrain do you travel on?

\begin{tabular}{|c|c|c|c|c|}
\hline Hilly places & Flat areas & $\begin{array}{l}\text { Rough stones } \\
\text { and sand }\end{array}$ & $\begin{array}{l}\text { Rough stones } \\
\text { and sand }\end{array}$ & $\begin{array}{l}\text { Hills, rough } \\
\text { stones, sand }\end{array}$ \\
\hline
\end{tabular}

What suggestions do you have to improve the tricycle?

To modify the To fix engine or To increase its I suggest to tricycle to move anything that speed and improve the on hilly places would hel climb hills. improve the tricycle by braking system. introducing an To travel on the hills. engine on it to easy movement and speed
Improve it by introducing gears. Engine to make it more fast.

\begin{tabular}{|c|c|c|c|c|}
\hline \multicolumn{5}{|c|}{ Was your device customized for you? What modifications were made? } \\
\hline $\begin{array}{l}\text { I was assessed } \\
\text { and } \\
\text { measurements } \\
\text { were done. }\end{array}$ & $\begin{array}{l}\text { I was assessed } \\
\text { and it was } \\
\text { measured to my } \\
\text { size. }\end{array}$ & $\begin{array}{l}\text { Yes the seat was } \\
\text { measured and } \\
\text { the distance } \\
\text { between the } \\
\text { wheels. }\end{array}$ & $\begin{array}{l}\text { Yes } \\
\text { measurements } \\
\text { were made on } \\
\text { me. }\end{array}$ & $\begin{array}{l}\text { Yes the frame } \\
\text { and seat were } \\
\text { measured after } \\
\text { assessing my } \\
\text { size and } \\
\text { disability levels. }\end{array}$ \\
\hline
\end{tabular}

\section{Do you have anything that you would like to add?}

I have liked my

tricycle because it has able me to move to market and visit friends.

\section{I need a carrier} on my tricycle to help me carry things from the market and also taking items to the market.
The tricycle frames are weak not, strong enough to support me for long time. Materials used rust, making the device weak.
I suggest the tricycle to have a shelter to avoid sunshine and rain. and rain.
The tricycle should have a shelter built on the frames to reduce on the sunshine that heat too much here. 


\section{Appendix C: National Production Costs in Kasese}

From July 2015.

\begin{tabular}{|c|c|}
\hline Part & Price \\
\hline 75mm MS Tubing & $5,000 \cup G X / 7 m$ \\
\hline $3 \mathrm{~mm}$ MS rack (tricycle) & 5,000 UGX \\
\hline $635 \mathrm{~mm}$ rim w/ spokes and freewheel hub & 32,000 UGX \\
\hline $635 \mathrm{~mm}$ tire & 18,000 UGX \\
\hline $635 \mathrm{~mm}$ inner tube & $6,000 \cup G X$ \\
\hline Cog (tricycle) & 16,000 UGX \\
\hline Fork (tricycle) & 15,000 UGX \\
\hline Crank (tricycle) & 15,000 UGX \\
\hline Chain (tricycle) & 20,000 UGX \\
\hline Foam & 11,000 UGX \\
\hline Fabric & 10,000 UGX \\
\hline Wood & $5,000 \cup G X$ \\
\hline
\end{tabular}

